\title{
A Nonlinear Control Strategy for DC-DC Converter with Unknown Constant Power Load Using Damping and Interconnection Injecting
}

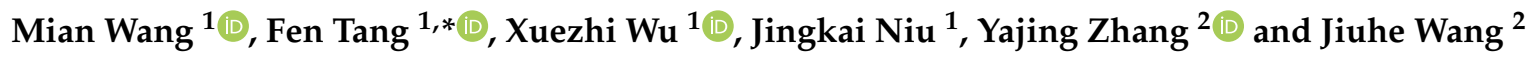 \\ 1 National Active Distribution Network Technology Research Center, Beijing Jiaotong University, \\ Beijing 100044, China; 17117421@bjtu.edu.cn (M.W.); xzhwu@bjtu.edu.cn (X.W.); 17117420@bjtu.edu.cn (J.N.) \\ 2 School of Automation, Beijing Information Science and Technology University, Beijing 100192, China; \\ zhangyajing@bistu.edu.cn (Y.Z.); wjhyhrwm@163.com (J.W.) \\ * Correspondence: fent@bjtu.edu.cn; Tel.: +86-135-8158-7732
}

check for updates

Citation: Wang, M.; Tang, F.; Wu, X.; Niu, J.; Zhang, Y.; Wang, J. A Nonlinear Control Strategy for DC-DC Converter with Unknown Constant Power Load Using Damping and Interconnection Injecting. Energies 2021, 14, 3031. https://doi.org/10.3390/en14113031

Academic Editors: Tibor Vince and Dobroslav Kovac

Received: 26 April 2021

Accepted: 20 May 2021

Published: 24 May 2021

Publisher's Note: MDPI stays neutral with regard to jurisdictional claims in published maps and institutional affiliations.

Copyright: (c) 2021 by the authors. Licensee MDPI, Basel, Switzerland. This article is an open access article distributed under the terms and conditions of the Creative Commons Attribution (CC BY) license (https:/ / creativecommons.org/licenses/by/ $4.0 /)$.

\begin{abstract}
DC-DC converters with constant power loads are mostly used in DC microgrids. Negative impedance and large disturbances of constant power loads may lead to the instability of DC-DC converters. To address this issue, a nonlinear control strategy consisting of an improved passivitybased controller and nonlinear power observer is proposed in this paper. First, an improved passivitybased controller is designed based on the port-controlled Hamiltonian with dissipation model. By proper damping and interconnection injecting, the fast dynamic response of output voltage and stability of the DC-DC converter is achieved. Second, the constant power load is observed by a nonlinear power observer, which is adopted to estimate the power variation of the constant power load within a small settling time and improve the adaptability of the DC-DC converter under power disturbance. Finally, the simulation and experimental results are presented, which illustrate the proposed control strategy not only ensures the stability of the DC-DC converter under large disturbances, but also can track the desired operating point with low voltage overshoot in no more than 10 milliseconds.
\end{abstract}

Keywords: DC-DC converter; constant power load; nonlinear control strategy; improved passivitybased controller; damping and interconnection injecting; nonlinear power observer

\section{Introduction}

With the development of the DC Microgrid (DM), the DM is becoming an effective way of distributing power supplies [1-3]. Meanwhile, the DC-DC converters (DDCs) are becoming increasingly common and play an important role in the DM due to their advantages in efficiency, flexibility, isolation, controllability, etc. [4].

The typical diagram of DM is shown in Figure 1; the DC sources and loads are commonly connected to DC BUS through the DDCs. The DDC is acting as a load from the input side and exhibits the constant power load (CPL) behavior. The negative impedance characteristic of CPL behavior [5,6] will lead to the instability of the DDC [7,8]. Therefore, it is necessary to develop some advanced control methods which can eliminate the influence of negative impedance on the DDC, achieve the fast dynamic response, and guarantee the DDC stability.

To solve the instability problem of the CPL, linear control methods have been introduced in the literature. In [9-11], the small signal model is established in order to analyze the influence of CPL on the stability of the DDC, and the virtual impedance method is proposed to realize the stability of the DDC with CPL. However, as the small signal model is only applicable to linear systems or linearized systems near the desired equilibrium point, the accuracy of the model will decrease in the case of large disturbances [12]. Furthermore, the traditional linear control strategy only provides an accurate control performance in 
close proximity to the desired equilibrium point and has a slow dynamic response when the CPL changes significantly $[13,14]$. In summary, research on the stability and control of the DDC using the small signal model has some limitations. Therefore, the numerous nonlinear control strategies are introduced based on large signal.

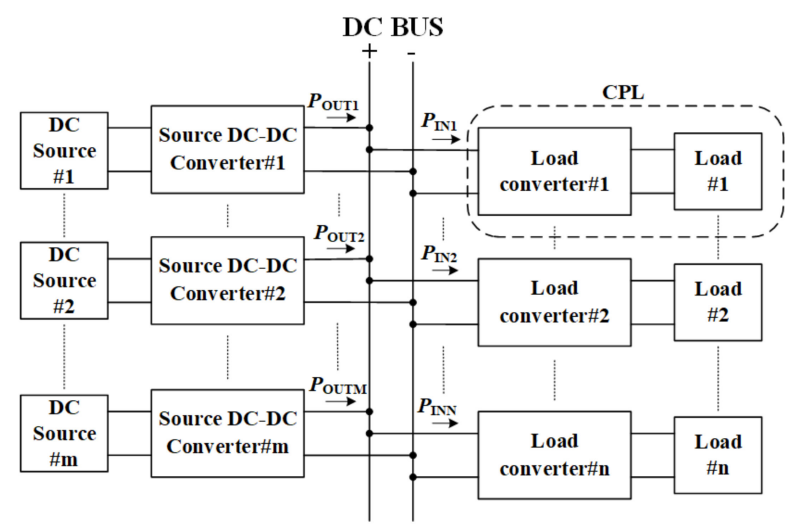

Figure 1. Typical diagram of DM.

Based on the affine nonlinear model and feedback linearization control theory [15], the state feedback controller and input/output feedback linearization controller of the DDC with CPL are designed in $[16,17]$, which improve the dynamic response of the converter and enhance the stability of DC voltage. However, they need full state measurement, and have complex controllers and a large dependence on parameters. In order to improve the disturbance rejection ability of the DDC, the active disturbance rejection controller (ADRC) [18] with CPL is designed in [19]; this improves the performance of the converter and has the robustness to face various disturbances and uncertain factors. Although satisfactory disturbance rejection performance of the DDC can be obtained by ADRC, there are many parameters of the controller which need to be determined, and the optimization of these parameters is difficult. The sliding-mode duty-ratio controller is proposed in [20], which can maintain the stability of the DDC in the operating domain under the significant changes in load power and input voltage, and it improves the dynamic response and steady performance of the DDC. However, the controller is very complex, and the output voltage fluctuation of the DDC is large. Moreover, the switching frequency of a sliding-mode controller is not fixed, and the filter design is difficult. In [21], the backstepping controller is designed in order to achieve better dynamic performance and robustness of the DDC. However, the virtual controller needs to be differentiated repeatedly, and becomes complex with the increase in system order.

The passivity-based controller (PBC) [22] has been widely employed in many physical systems $[23,24]$ based on the energy function, and is an effective practical nonlinear control technique due to its simplicity, efficiency, and ease of implementation in comparison to the other nonlinear control techniques. The various types of PBC are designed in [25-27] based on the Euler-Lagrange (EL) model and the port-controlled Hamiltonian with dissipation (PCHD) model, which can ensure the large-range stability and reliability of the DDC. However, the output voltage has the steady-state error, and the transient stability of the DDC will be reduced under the variations and uncertainties of system parameters and operating conditions. In [28], the interconnection and damping assignment passivity-based controller (IDA-PBC) is designed based on the PCHD model with PI controller. It can guarantee the stability of the DDC under disturbance. However, the global stability of the DDC cannot be guaranteed, and its dynamic response is slow. In [29], the stability of the cascaded LC filter DDC is realized by the modified IDA-PBC based on the port-controlled Hamiltonian (PCH). However, the control law of this strategy is complex, and does not allow for the principle of parameters design.

To obtain excellent dynamic and steady characteristics of the DDC with CPL, this paper will utilize the DC-DC boost converter (DDBC) to study the stability and control based on 
the passivity. An improved passivity-based controller (IPBC) is proposed to realize the dynamic response and stability of DDBC based on the PCHD model, and the damping and interconnection injecting in IPBC is determined according to the dynamic energy storage function. Meanwhile, the nonlinear power observer (NPO) is used with IPBC, which can improve the adaptability of DDBC, and ensure the desired operating point tracking when CPL and input voltage change. In summary, the nonlinear control strategy which consists of the IPBC and NPO is proposed in this paper. Finally, the comparative study of the proposed control strategy with IDA-PBC and $\mathrm{PBC}$ is verified by detailed simulation and experimental results in this paper, suggesting that the DDBC has a better dynamic response characteristic while ensuring stability by using the proposed control strategy.

This paper is organized as follows. The stability analysis of DDBC with CPL based on passivity is analyzed in Section 2. The IPBC based on PCHD model is proposed in Section 3. The NPO of unknown CPL is designed and the selection principle of IPBC parameters is analyzed in Section 4. Subsequently, some realistic simulation and experimental results are given in Section 5. The conclusion of this paper appears in Section 6.

\section{Stability Analysis of DDBC Converter with CPL}

\subsection{Constant Power Load Characteristic}

The $U-I$ characteristic of a CPL is illustrated in Figure 2.

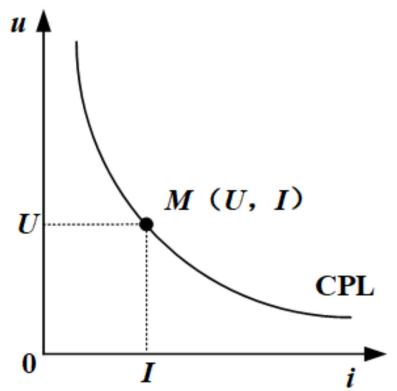

Figure 2. The $U-I$ Characteristic Curve of CPL.

The voltage-current characteristic of a CPL is given by:

$$
i=\frac{P_{\mathrm{CPL}}}{u}
$$

where $P_{\mathrm{CPL}}$ is the power of $\mathrm{CPL}, i$ and $u$ are the instantaneous values of input current and voltage of the CPL. For a given operating point $M(U I)$, the rate of change in current can be obtained from (1) as follows:

$$
\frac{\partial i}{\partial u}=-\frac{P_{\mathrm{CPL}}}{U^{2}}
$$

Therefore, the curve representing the current versus voltage for a CPL can be approximated by a straight line tangent to the curve at the operating point. The equation for this line is as follows:

$$
i=2 \frac{P_{\mathrm{CPL}}}{U}-\frac{P_{\mathrm{CPL}}}{U^{2}} u
$$

According to (3), at a given operating point, a CPL can be equivalent to a controlled current source $I_{\mathrm{CPL}}$ in parallel with a negative resistance. $R_{\mathrm{CPL}}, I_{\mathrm{CPL}}$ and $R_{\mathrm{CPL}}$ are given by the following:

$$
\left\{\begin{aligned}
I_{\mathrm{CPL}} & =\frac{2 P_{\mathrm{CPL}}}{U} \\
R_{\mathrm{CPL}} & =-\frac{U^{2}}{P_{\mathrm{CPL}}}
\end{aligned}\right.
$$

From (4), the CPL has a negative impedance characteristic and this will pose negative impact on system performance [30]. 


\subsection{Stability Analysis of DDBC with CPL Based on Passivity}

\subsubsection{Effect of CPL on Stability of DDBC}

The power circuit of DDBC with CPL is shown in Figure 3, where $u_{\mathrm{S}}$ is the input voltage; $L$ and $C$ are the inductance and capacitance in DDBC, respectively; $i_{\mathrm{L}}$ and $i_{\mathrm{C}}$ are the inductor and capacitor current, respectively; $u_{C}$ is the output voltage; $i_{\mathrm{CPL}}$ is the current of CPL; $T$ is insulated gate bipolar transistor; $s_{\mathrm{g}}$ is the gate drive signal of $T$; and $D$ is the diode. To facilitate the analysis, the components are considered as ideal devices.

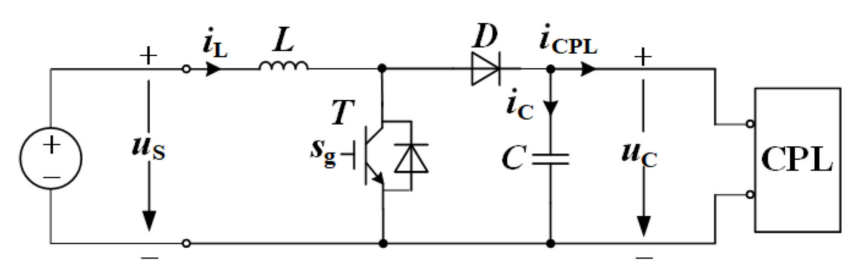

Figure 3. Power Circuit of Boost Converter with CPL.

According to the principle of volt-second balancing, the average switch model of DDBC [31] can be given as follows:

$$
\left\{\begin{aligned}
L \frac{d i_{\mathrm{L}}}{d t} & =(\sigma-1) u_{\mathrm{C}}+u_{\mathrm{S}} \\
C \frac{d u_{\mathrm{C}}}{d t} & =(1-\sigma) i_{\mathrm{L}}-\frac{P_{\mathrm{CPL}}}{u_{\mathrm{C}}}
\end{aligned}\right.
$$

where $\sigma$ is the duty ratio of $s_{\mathrm{g}}$.

According to (5), the phase portrait and simulation results of DDBC can be concluded when the desired average output voltage $U_{\mathrm{CD}}=60 \mathrm{~V}$, desired average inductor current $I_{\mathrm{LD}}=2 \mathrm{~A}$, switching frequency $f=10 \mathrm{kHz}, P_{\mathrm{CPL}}=60 \mathrm{~W}, \sigma=0.5, L=2 \mathrm{mH}, \mathrm{C}=940 \mu \mathrm{F}$, and $u_{\mathrm{S}}=30 \mathrm{~V}$.

As shown in Figure 4, the phase portrait displays clearly the characteristics of DDBC with a CPL. The blue line is the trajectory of the state variable $\left(i_{L}, u_{C}\right)$; the blue arrow indicates the evolving direction of the trajectory. The state plane is divided into two regions by the separatrix: $S$. The region above the separatrix is a stable region, and the region below is an unstable region; the DDBC is unstable when the state variable is in the unstable region. Moreover, the trajectory will converge to a limit cycle when the state variable is in the stable region. Due to the existence of the limit cycle, the DDBC cannot operate stably at the desired voltage and current. As can be seen in Figure 5, the state variables oscillate in a periodic steady state. When the oscillation is significant, it is easy to damage the switching devices and capacitors, and result in the damage of the DDBC.

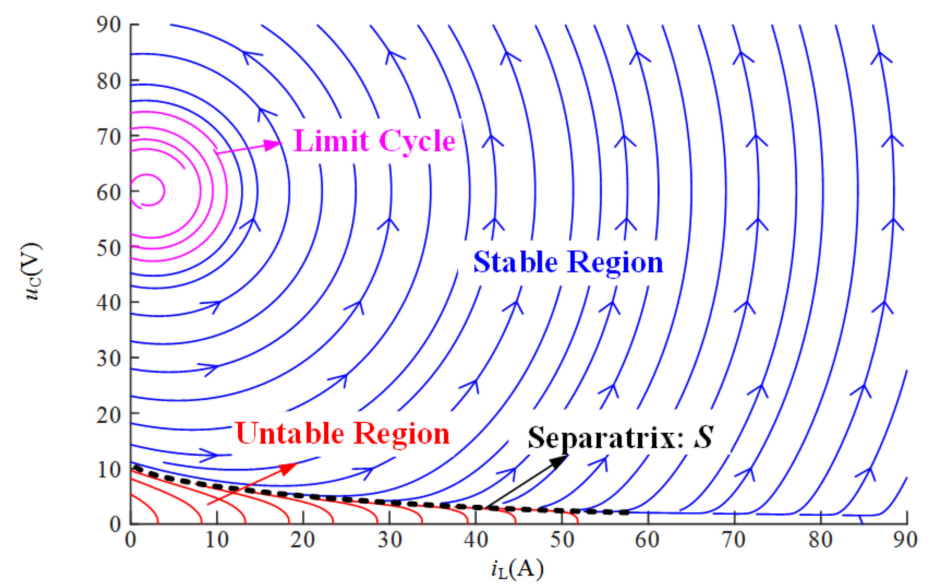

Figure 4. Phase portrait of DDBC. 


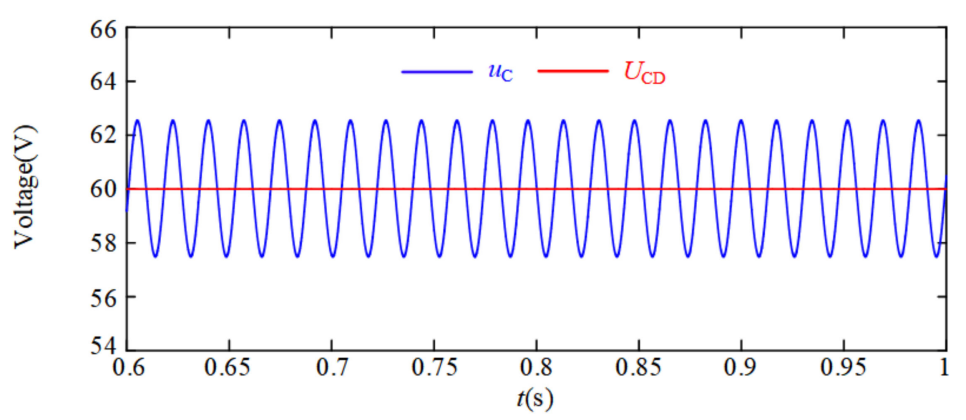

(a)

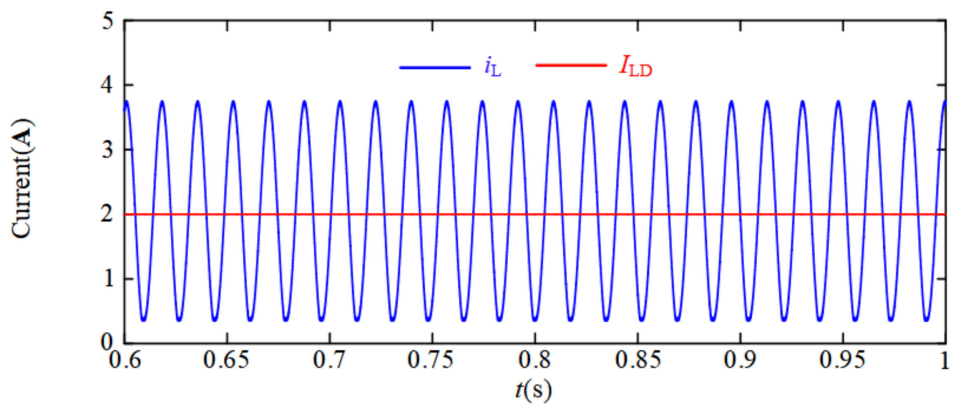

(b)

Figure 5. Voltage and current of DDBC under open control. (a) output voltage and desired output voltage; (b) inductor current, CPL current, desired inductor current, and CPL current.

\subsubsection{Passivity Analysis of DDBC with CPL}

Consider the system with input $u$ and output $y$ as follows:

$$
\left\{\begin{array}{c}
\dot{x}=f(x, u) \\
y=h(x)
\end{array}\right.
$$

The system depicted in (6) exists a nonnegative storage function $H(x)$ and a positive definite function $Q(x)$ such that:

$$
H(x(t))-H(x(0)) \leq \int_{0}^{t} \boldsymbol{u}^{\mathrm{T}} \boldsymbol{y} d \tau-\int_{0}^{t} Q(x) d \tau, t>0
$$

or

$$
\dot{H}(\boldsymbol{x}) \leq \boldsymbol{u}^{\mathrm{T}} \boldsymbol{y}-Q(\boldsymbol{x})
$$

If $\dot{H}(x)<0$ when $Q(x)>0$, the system is said to be strictly passive; it must be internally stable [32].

From (5), it is further changed to:

$$
\left\{\begin{aligned}
L i_{\mathrm{L}} \frac{d i_{\mathrm{L}}}{d t} & =(\sigma-1) u_{\mathrm{C}} i_{\mathrm{L}}+u_{\mathrm{S}} i_{\mathrm{L}} \\
C u_{\mathrm{C}} \frac{d u_{\mathrm{C}}}{d t} & =(1-\sigma) u_{\mathrm{C}} i_{\mathrm{L}}-P_{\mathrm{CPL}}
\end{aligned}\right.
$$

According to the characteristic of CPL, the $P_{\mathrm{CPL}}=i_{\mathrm{CPL}}{ }^{2} R_{\mathrm{CPL}}$ and $R_{\mathrm{CPL}}=-u_{\mathrm{C}}{ }^{2} / P_{\mathrm{CPL}}$ in $\mathrm{DDBC}$ with $\mathrm{CPL}$, the following equation can be obtained by combining the two equations in (9).

$$
L i_{\mathrm{L}} \frac{d i_{\mathrm{L}}}{d t}+C u_{\mathrm{C}} \frac{d u_{\mathrm{C}}}{d t}=u_{\mathrm{S}} i_{\mathrm{L}}-i_{\mathrm{CPL}}^{2} R_{\mathrm{CPL}}
$$


The energy storage function can be expressed as:

$$
\begin{gathered}
H_{\mathrm{O}}(t)=H_{\mathrm{L}}(t)+H_{\mathrm{C}}(t) \\
H_{\mathrm{L}}(t)=\frac{1}{2} L i_{\mathrm{L}}^{2}(t) \\
H_{\mathrm{C}}(t)=\frac{1}{2} C u_{\mathrm{C}}^{2}(t)
\end{gathered}
$$

From (10) and (11), $\dot{H}_{\mathrm{O}}(t)$ can be written as:

$$
\dot{H}_{\mathrm{O}}(t)=u_{\mathrm{S}} i_{\mathrm{L}}-i_{\mathrm{CPL}}^{2} R_{\mathrm{CPL}}
$$

Let the $u_{\mathrm{S}}=u, i_{\mathrm{L}}=\boldsymbol{y}$, according to (8) and (12), $Q(x)<0$, the DDBC with CPL is nonpassive and is the reason why the DDBC cannot work at a constant stable state. Therefore, in order to eliminate the limit cycle in Figure 4 and realize the stable work of the DDBC, the DDBC needs to be passivated.

\section{IPBC of DDBC Based on PCHD Model}

\subsection{PCHD Model of DDBC}

In order to establish the PCHD model of DDBC, let inductive magnetic flux $x_{1 \mathrm{p}}=\varphi_{\mathrm{L}}=L i_{\mathrm{L}}$, capacitive charge $x_{2 \mathrm{p}}=q_{\mathrm{C}}=C u_{\mathrm{C}}$, then take the vector as $x_{\mathrm{p}}=\left[x_{1 \mathrm{p}} x_{2 \mathrm{p}}\right]^{\mathrm{T}}=\left[L i_{\mathrm{L}} C u_{\mathrm{C}}\right]^{\mathrm{T}}$, the

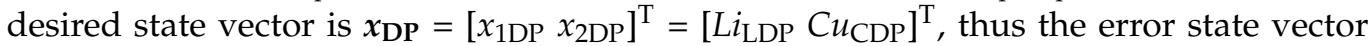
$x_{\mathrm{E}}=x_{\mathbf{P}}-x_{\mathrm{DP}}, x_{\mathrm{E}}=\left[x_{1 \mathrm{E}} x_{2 \mathrm{E}}\right]^{\mathrm{T}}=\left[L i_{l} C u_{\mathrm{c}}\right]^{\mathrm{T}}, i_{l}$ and $u_{\mathrm{c}}$ are the error of the inductor current and output voltage, respectively. Therefore, (5) can be changed to:

$$
\left\{\begin{array}{l}
\dot{x}_{1 \mathrm{P}}=\dot{x}_{1 \mathrm{E}}=-\frac{x_{2 \mathrm{P}}}{\mathrm{C}}+\sigma \frac{x_{2 \mathrm{P}}}{\mathrm{C}}+u_{\mathrm{S}} \\
\dot{x}_{2 \mathrm{P}}=\dot{x}_{2 \mathrm{E}}=\frac{x_{1 \mathrm{P}}}{L}-\sigma \frac{x_{1 \mathrm{P}}}{L}-\frac{C P_{\mathrm{PPL}}}{x_{2 \mathrm{P}}}
\end{array}\right.
$$

According to (13), the PCHD model of DDBC is:

$$
\left\{\begin{array}{c}
\dot{x}_{\mathrm{E}}=(\boldsymbol{J}-\boldsymbol{R}) \frac{\partial H\left(x_{\mathrm{P}}\right)}{\partial x_{\mathrm{P}}}+J_{\boldsymbol{\sigma}} x_{\mathbf{P}}+u \\
y=\frac{\partial H\left(x_{\mathrm{P}}\right)}{\partial x_{\mathrm{P}}}
\end{array}\right.
$$

where $J$ is a skew symmetric matrix and satisfies $J=-J^{\mathrm{T}}$, and $J=\left(\begin{array}{cc}0 & -1 \\ 1 & 0\end{array}\right), \boldsymbol{x}_{\mathbf{P}}^{\mathrm{T}} \boldsymbol{J} \boldsymbol{x}_{\mathbf{P}}=0$,

$$
\boldsymbol{R}=\left(\begin{array}{cc}
0 & 0 \\
0 & \frac{C^{2} P_{\mathrm{CPL}}}{x_{2 \mathrm{P}}{ }^{2}}
\end{array}\right) ; H\left(x_{\mathbf{P}}\right)=\frac{1}{2 L} x_{1 \mathrm{P}}{ }^{2}+\frac{1}{2 \mathrm{C}} x_{2 \mathrm{P}}{ }^{2}, \frac{\partial H\left(x_{\mathbf{P}}\right)}{\partial x_{\mathbf{P}}}=\left(\frac{x_{1 \mathrm{P}}}{L} \frac{x_{2 \mathrm{P}}}{C}\right)^{\mathrm{T}} ; \boldsymbol{u}=\left(\begin{array}{c}
u_{\mathrm{S}} \\
0
\end{array}\right) ; J_{\boldsymbol{\sigma}}=\left(\begin{array}{cc}
0 & \frac{\sigma}{\mathrm{C}} \\
-\frac{\sigma}{L} & 0
\end{array}\right)
$$

\subsection{IPBC Design of $D D B C$}

In order to overcome the non-passivity and realize the stable work of the DDBC, interconnection and damping injecting are added in (16). If there is a dynamic energy storage function $H_{\mathrm{p}}\left(\boldsymbol{x}_{\mathrm{P}}\right)$ and a skew symmetric matrix $\boldsymbol{J}_{\mathbf{P}}=\boldsymbol{J}+\boldsymbol{J}_{\mathbf{a}}$, where $\boldsymbol{J}_{\mathbf{a}}=\left(\begin{array}{cc}0 & -j_{\mathrm{a}} \\ j_{\mathrm{a}} & 0\end{array}\right)$, $j_{\mathrm{a}}>0$, and a positive definite matrix $\boldsymbol{R}_{\mathbf{P}}=\boldsymbol{R}+\boldsymbol{R}_{\mathbf{a}}$, where $\boldsymbol{R}_{\mathbf{a}}=\left(\begin{array}{cc}r_{\mathrm{a}} & 0 \\ 0 & g_{\mathrm{a}}\end{array}\right), r_{\mathrm{a}}>0, g_{\mathrm{a}}>0$, $r_{\mathrm{a}}, g_{\mathrm{a}}$ are positive damping injecting and conductance injecting, the controller of DDBC is taken as

$$
\left\{\begin{array}{c}
\boldsymbol{u}=\left(\boldsymbol{J}_{\mathbf{P}}-\boldsymbol{R}_{\mathbf{P}}\right) \frac{\partial H_{\mathrm{P}}\left(x_{\mathbf{P}}\right)}{\partial x_{\mathbf{P}}}-(\boldsymbol{J}-\boldsymbol{R}) \frac{\partial H\left(x_{\mathbf{P}}\right)}{\partial x_{\mathbf{P}}}-J_{\boldsymbol{\sigma}} x_{\mathbf{P}} \\
\dot{x}_{\mathrm{E}}=\left(\boldsymbol{J}_{\mathbf{P}}-\boldsymbol{R}_{\mathbf{P}}\right) \frac{\partial H_{\mathrm{P}}\left(x_{\mathbf{P}}\right)}{\partial x_{\mathbf{P}}}
\end{array}\right.
$$

From (15), the dynamic energy storage function $H_{\mathrm{p}}\left(\boldsymbol{x}_{\mathbf{P}}\right)$ can be written as

$$
H_{\mathrm{p}}\left(x_{\mathbf{P}}\right)=H_{\mathrm{p}}\left(x_{\mathrm{E}}\right)=\frac{1}{2} x_{\mathrm{E}}^{T} \boldsymbol{M}_{\mathbf{P}} x_{\mathrm{E}}=\frac{1}{2 L} x_{1 \mathrm{E}}^{2}+\frac{1}{2 C} x_{2 \mathrm{E}}^{2}
$$


where $\boldsymbol{M}_{\mathbf{P}}=\operatorname{diag}(1 / L 1 / C)$.

According (15) and (16), $\dot{H}_{\mathrm{p}}\left(x_{\mathbf{P}}\right)$ can be obtained

$$
\begin{aligned}
\dot{H}_{\mathrm{p}}\left(x_{\mathbf{P}}\right) & =\dot{H}_{\mathrm{p}}\left(x_{\mathrm{E}}\right)=x_{\mathrm{E}}^{T} \boldsymbol{M}_{\mathbf{P}} \dot{x}_{E} \\
= & \left(\frac{\partial H_{\mathrm{p}}\left(x_{\mathrm{E}}\right)}{\partial x_{\mathrm{E}}}\right)^{T}\left(\boldsymbol{J}_{\mathbf{P}}-\boldsymbol{R}_{\mathbf{P}}\right) \frac{\partial H_{\mathrm{P}}\left(x_{\mathrm{E}}\right)}{\partial x_{\mathrm{E}}} \\
= & -\left(r_{\mathrm{a}} i_{l}^{2}+\left(g_{\mathrm{a}}+\frac{\mathrm{C}^{2} P_{\mathrm{CPL}}}{x_{2 \mathrm{P}}^{2}}\right) u_{\mathrm{c}}^{2}\right)<0
\end{aligned}
$$

According to (17), $\boldsymbol{M}_{\mathbf{P}}$ is a positive-definite matrix and $\dot{H}_{\mathbf{p}}\left(x_{\mathbf{P}}\right)<0, \dot{H}_{\mathbf{p}}\left(x_{\mathbf{P}}\right)$ is qualified as a Lyapunov function [33], and the passivation of the DDBC with CPL is realized by (15). Therefore, (15) is the IPBC.

From (15), the duty cycle corresponding to the IPBC is represented by

$$
\left\{\begin{array}{c}
u_{\mathrm{S}}=-\left(1+j_{\mathrm{a}}\right) u_{\mathrm{c}}-r_{\mathrm{a}} i_{l}+(1-\sigma) u_{\mathrm{C}} \\
0=\left(1+j_{\mathrm{a}}\right) i_{l}-\left(g_{\mathrm{a}}+\frac{P_{\mathrm{CPP}}}{u_{\mathrm{C}}^{2}}\right) u_{\mathrm{c}}+\frac{P_{\mathrm{CPL}}}{u_{\mathrm{C}}}-(1-\sigma) i_{\mathrm{L}}
\end{array}\right.
$$

According to the direction of energy flow, the $i_{\mathrm{L}}$ should be established first, and the $u_{\mathrm{C}}$ should be established later. It can be obtained from the first equation of Equation (19):

$$
\sigma=1-\frac{u_{\mathrm{S}}+\left(1+j_{\mathrm{a}}\right) u_{\mathrm{c}}+r_{\mathrm{a}} i_{l}}{u_{\mathrm{C}}}=1-\frac{u_{\mathrm{S}}+\left(1+j_{\mathrm{a}}\right)\left(u_{\mathrm{C}}-U_{\mathrm{CD}}\right)+r_{\mathrm{a}}\left(i_{\mathrm{L}}-I_{\mathrm{LD}}\right)}{u_{\mathrm{C}}}
$$

where $I_{\mathrm{LD}}=P_{\mathrm{CPL}} / U_{\mathrm{SD}}$.

From (19), duty ratio $\sigma$ is associated with $u_{\mathrm{C}}$ and $i_{\mathrm{L}}$, and a correlation degree is decided by $j_{\mathrm{a}}$ and $r_{\mathrm{a}}$. Therefore, the good dynamic and steady state performance of DDBC is obtained by selecting proper $j_{\mathrm{a}}$ and $r_{\mathrm{a}}$.

\section{Unknown Nonlinear Power Observer and Preferences in IPBC}

\subsection{Nonlinear Power Observer of Unknown CPL}

In practice, the power of CPL may be changed under the influences of various uncertain factors, and the operating point of DDBC may be changed. Therefore, the nonlinear power observer of CPL is introduced in the proposed control strategy to adjust the $I_{\mathrm{LD}}$ in real time to ensure the operating point tracking. Learning from [34,35], the NPO of CPL for DDBC can be expressed as

$$
\left\{\begin{array}{c}
\hat{P}_{\mathrm{CPL}}=-\frac{1}{2} \gamma C x_{2}^{2}+\hat{P}_{\mathrm{A}} \\
\dot{\hat{P}}_{\mathrm{A}}=\gamma x_{1} x_{2}(1-\sigma)+\frac{1}{2} \gamma^{2} C x_{2}^{2}-\gamma \hat{P}_{\mathrm{A}}
\end{array}\right.
$$

where $\hat{P}_{\mathrm{CPL}}$ is the observed value of $P_{\mathrm{CPL}}, \gamma$ is a NPO gain.

Let power observed error be:

$$
\widetilde{P}_{\mathrm{CPL}}=\hat{P}_{\mathrm{CPL}}-P_{\mathrm{CPL}}
$$

According to (21) and (5), $\dot{\widetilde{P}}_{\mathrm{CPL}}$ is transformed as:

$$
\begin{aligned}
\dot{\widetilde{P}}_{\mathrm{CPL}} & =\dot{\hat{P}}_{\mathrm{CPL}}-\dot{P}_{\mathrm{CPL}}=\dot{\hat{P}}_{\mathrm{CPL}} \\
& =-\gamma\left(\hat{P}_{\mathrm{CPL}}-P_{\mathrm{CPL}}\right)=-\gamma \widetilde{P}_{\mathrm{CPL}}
\end{aligned}
$$

Equation (22) can be written compactly as:

$$
\left\{\begin{array}{c}
\dot{\widetilde{P}}_{\mathrm{CPL}}+\gamma \widetilde{P}_{\mathrm{CPL}}=0 \\
\widetilde{P}_{\mathrm{CPL}}=e^{-\gamma t} \widetilde{P}_{\mathrm{CPL}}(0)
\end{array}\right.
$$


Equation (23) shows that $\widetilde{P}_{\mathrm{CPL}}$ goes to zero exponentially. How fast $\widetilde{P}_{\mathrm{CPL}}$ goes to zero depends on the magnitude of $\gamma$. The larger $\gamma$ is, the faster $\widetilde{P}_{\mathrm{CPL}}$ goes to zero, and $\hat{P}_{\mathrm{CPL}}=P_{\mathrm{CPL}}$. Furthermore, the dynamic response of the NPO needs to be fast enough to adjust the $I_{\mathrm{LD}}$ in real time, and ensure the CPL tracking, and the large NPO gain, is selected in general [36]. Therefore, an appropriate $\gamma$ can be selected to realize effective real-time observation of $\hat{P}_{\mathrm{CPL}}$ on unknown $P_{\mathrm{CPL}}$, and can ensure the operating point tracking when CPL changes.

\subsection{Design of Damping Injecting and Conductance Injecting for IPBC}

The convergence rate of the output voltage and inductor current is affected by the values of damping injecting $r_{\mathrm{a}}$ and conductance injecting $g_{\mathrm{a}}$. Therefore, the parameters are designed from the perspective of energy conservation.

Combining (16) and (17), $\dot{H}_{\mathrm{p}}(\boldsymbol{x})$ can be expressed as:

$$
\dot{H}_{\mathrm{p}}\left(x_{\mathrm{P}}\right)=\dot{H}_{\mathrm{p}}\left(x_{\mathrm{E}}\right)=\frac{1}{2} L \frac{d i_{l}^{2}}{d t}+\frac{1}{2} C \frac{d u_{\mathrm{c}}^{2}}{d t}=-\left(r_{\mathrm{a}} i_{l}^{2}+\left(g_{\mathrm{a}}+\frac{C^{2} P_{\mathrm{CPL}}}{x_{2 \mathrm{P}}^{2}}\right) u_{\mathrm{c}}^{2}\right)
$$

Equation (24) is further changed to:

$$
\dot{H}_{\mathrm{p}}\left(x_{\mathrm{E}}\right)=-\beta H_{\mathrm{p}}\left(x_{\mathrm{E}}\right)=r_{\mathrm{a}} i_{l}^{2}+\left(g_{\mathrm{a}}+\frac{C^{2} P_{\mathrm{CPL}}}{x_{2}^{2}}\right) u_{\mathrm{c}}^{2}
$$

where $\beta>0$.

Equation (25) can be transformed as:

$$
\dot{H}_{\mathrm{p}}\left(\boldsymbol{x}_{\mathrm{E}}\right)+\beta H_{\mathrm{p}}\left(\boldsymbol{x}_{\mathrm{E}}\right)=0
$$

and

$$
H_{\mathrm{p}}\left(x_{\mathrm{E}}\right)=H_{\mathrm{p}}(0) e^{-\beta t}
$$

Equation (27) shows that $H_{\mathrm{P}}(x)$ can approach zero exponentially, and the convergence rate of $H_{\mathrm{P}}(x)$ depends on $\beta$. The larger $\beta$ is, the faster $H_{\mathrm{P}}(x)$ will approach zero. As the $H_{\mathrm{P}}(x)$ goes to zero, desired output voltage and inductor current will be realized.

By substituting (16) into (25), it can be expressed as:

$$
r_{\mathrm{a}} i_{l}^{2}+\left(g_{\mathrm{a}}+\frac{C^{2} P_{\mathrm{CPL}}}{x_{2 \mathrm{P}}^{2}}\right) u_{\mathrm{c}}^{2}=-\beta\left(\frac{1}{2} L i_{l}^{2}+\frac{1}{2} C u_{\mathrm{c}}^{2}\right)
$$

Originating from (28), $r_{\mathrm{a}}$ and $g_{\mathrm{a}}$ satisfy:

$$
\left\{\begin{array}{c}
\frac{1}{2} L \beta=-r_{\mathrm{a}} \\
\frac{1}{2} C \beta=-\left(g_{\mathrm{a}}+\frac{P_{\mathrm{CPL}}}{u_{\mathrm{C}}^{2}}\right)
\end{array}\right.
$$

Further, $\beta$ and $r_{\mathrm{a}}$ are selected by:

$$
\left\{\begin{array}{c}
\beta=-\left(\frac{2}{C}\left(g_{\mathrm{a}}+\frac{P_{\mathrm{CPL}}}{u_{\mathrm{C}}^{2}}\right)\right) \\
r_{\mathrm{a}}=\frac{L}{C}\left(g_{\mathrm{a}}+\frac{P_{\mathrm{CP}}}{u_{\mathrm{C}}^{2}}\right)
\end{array}\right.
$$

According to (30), $\alpha$ and $r_{\mathrm{a}}$ depend on $g_{\mathrm{a}}, P_{\mathrm{CPL}}$ and $u_{\mathrm{C}}$. In order to improve the robustness to the load and let $H_{\mathrm{P}}\left(x_{\mathrm{E}}\right)$ rapidly approach zero, a large $g_{\mathrm{a}}$ can be selected. $g_{\mathrm{a}}$ is determined by:

$$
g_{\mathrm{a}} \gg \frac{P_{\mathrm{CPL}}}{u_{\mathrm{C}}^{2}} \approx \frac{P_{\mathrm{CPL}}}{U_{\mathrm{CD}}^{2}}
$$


Therefore, $r_{\mathrm{a}}$ is mainly determined by $g_{\mathrm{a}}$ as $g_{\mathrm{a}}>P_{\mathrm{CPL}} /\left(u_{\mathrm{C}}{ }^{2}\right)$ according to (30) and (31). This means the tuning of $r_{\mathrm{a}}$ is not significantly affected by operating points to ensure the robustness to the load.

\subsection{Design of Interconnection Injecting for IPBC}

In order to analyze the ability of interconnection injecting $j_{\mathrm{a}}$ to track $U_{\mathrm{CD}}$ and $I_{\mathrm{LD}}$, substituting (19) into (5) results in a voltage equation of

$$
L \frac{d i_{l}}{d t}+r_{\mathrm{a}} i_{l}=-\left(1+j_{a}\right) u_{\mathrm{c}}
$$

It can be seen from (32) that $j_{\mathrm{a}}$ is mainly related to the voltage and current. According to (32), when $u_{\mathrm{C}}>0$ and $u_{\mathrm{C}}>U_{\mathrm{CD}}, i_{l}$ will become a negative incremental trend, which makes the $i_{\mathrm{L}}$ and $u_{\mathrm{C}}$ decrease; when $u_{\mathrm{C}}<0$ and $u_{\mathrm{C}}<U_{\mathrm{CD}}, i_{l}$ will become a positive incremental trend, which makes the $i_{\mathrm{L}}$ and $u_{\mathrm{C}}$ increase. From the dynamic perspective, the regulation speed depends on $j_{\mathrm{a}}$. The larger $j_{\mathrm{a}}$ is, the faster the regulation is, which means smaller dynamic error and shorter regulation time. On the contrary, the smaller $j_{\mathrm{a}}$ will have the slower adjustment speed and lead to greater dynamic error. Thus, $j_{\mathrm{a}}$ can be selected according to the maximum change in CPL to obtain the desired transient response of DDBC.

In summary, the structure of the proposed control strategy is shown in Figure 6. The implementation procedures for the proposed control strategy are as follows:

(1) First, the parameters $\gamma, r_{\mathrm{a}}$, and $j_{\mathrm{a}}$ are designed according to (23), (30) and (31).

(2) Second, the power of CPL is estimated according to (20), and $I_{\mathrm{LD}}$ is calculated with the measured input voltage.

(3) Finally, the duty cycle is calculated according to (19) with determined parameters and measured inductor current, output voltage, and input voltage.

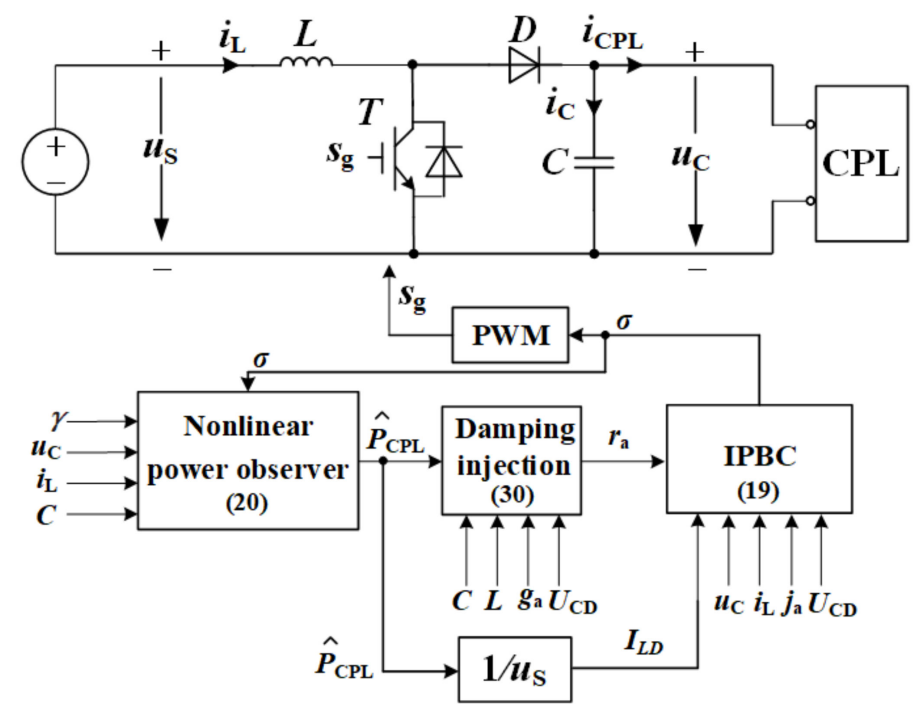

Figure 6. The structure of the proposed control strategy.

\section{Simulation and Experimental Results}

\subsection{Simulation Results}

The proposed control strategy in Figure 6 is simulated in MATLAB/Simulink to validate its effectiveness. The system parameters are listed in Table 1. First, the procedure for tuning design parameters is illustrated, then the simulation results under different operating conditions will be presented. 
Table 1. Simulation parameters of DDBC.

\begin{tabular}{ccc}
\hline Symbols & Parameter Names & Values \\
\hline$u_{\mathrm{S}}$ & Input voltage & $30 \mathrm{~V}$ \\
$U_{\mathrm{CD}}$ & Desired average output voltage & $60 \mathrm{~V}$ \\
$I_{\mathrm{LD}}$ & Desired average inductor current & $2 \mathrm{~A}$ \\
$P_{\mathrm{CPL}}$ & Rated power & $60 \mathrm{~W}$ \\
$\mathrm{C}$ & Capacitance & $940 \mu \mathrm{F}$ \\
$L$ & Inductance & $2 \mathrm{mH}$ \\
$f_{\mathrm{S}}$ & Switching frequency & $10 \mathrm{kHz}$ \\
$j_{\mathrm{a}}$ & Interconnection injecting & 7 \\
$r_{\mathrm{a}}$ & Positive damping injecting & 6.36 \\
$g_{\mathrm{a}}$ & Conductance injecting & 3 \\
$\gamma$ & Power observer gain & 2000 \\
\hline
\end{tabular}

\subsubsection{Tuning of Design Parameters}

\section{NPO Gain}

The proposed control strategy consists of NPO for the CPL estimation and IPBC for the output voltage regulation. The dynamic responses of the observed CPL variation and output voltage when the CPL steps from $60 \mathrm{~W}$ to $90 \mathrm{~W}$ and $90 \mathrm{~W}$ to $60 \mathrm{~W}$ at $0.5 \mathrm{~s}$ under different values of $\gamma(\gamma=50,200,500,1000$, and 2000) are shown in the following simulations.

It can be observed from Figures 7 and 8 that the NPO and $u_{\mathrm{C}}$ can track the CPL variation and $U_{\mathrm{CD}}$ with fast dynamic response, and the larger $\gamma$ will result in a faster convergence rate for output voltage and operating point tracking when the CPL changes. As the CPL steps, the power of the CPL and $U_{\mathrm{CD}}$ need to be tracked quickly to maintain DDBC stability, and the large power observer gain is typically selected [37]. Therefore, $\gamma$ can be selected as 2000 to ensure the faster dynamic response can be obtained. This set of the parameters will be used in the simulations and experiments below to verify the feasibility of the proposed control strategy, and show its advantage in terms of dynamic characteristics by comparing with other strategies.

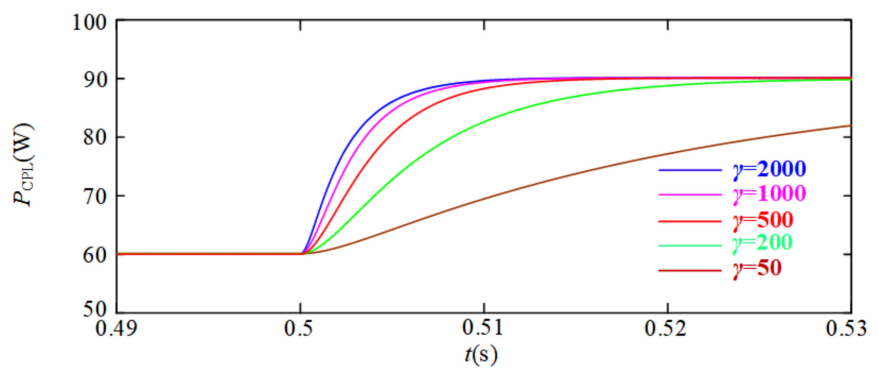

(a)

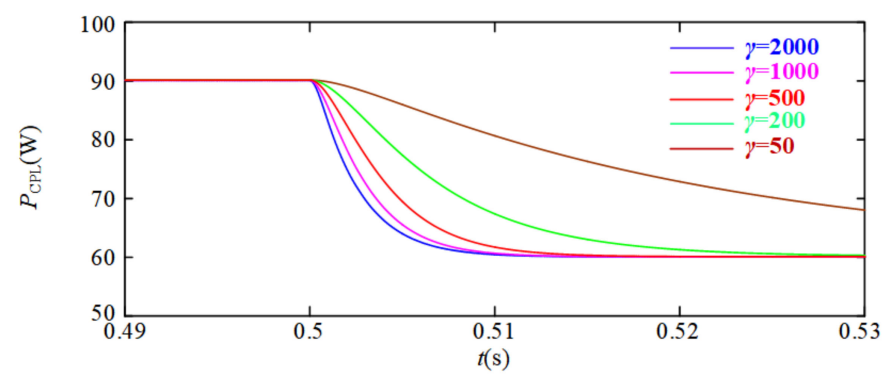

(b)

Figure 7. Simulated CPL observation of the different $\gamma$ when CPL steps up and down. (a) CPL: $60 \mathrm{~W}$ to $90 \mathrm{~W}$; (b) CPL: $90 \mathrm{~W}$ to $60 \mathrm{~W}$. 


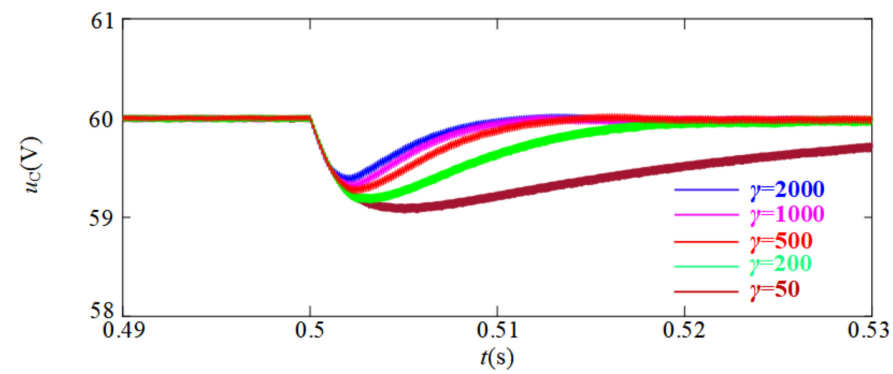

(a)

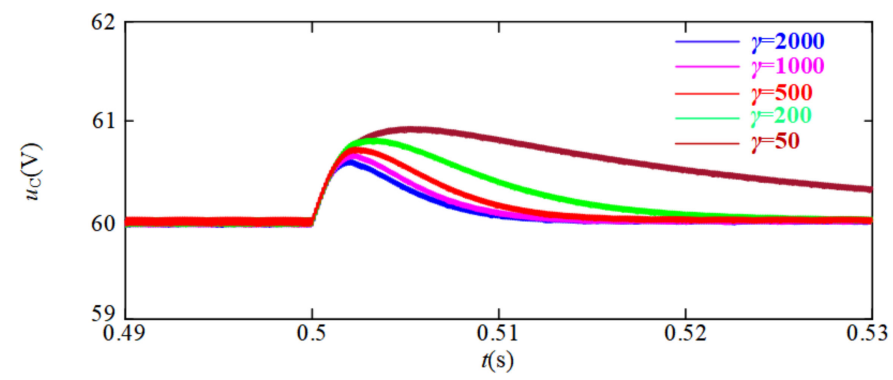

(b)

Figure 8. Simulated $u_{\mathrm{C}}$ responses of the different $\gamma$ when CPL steps up and down. (a) CPL: $60 \mathrm{~W}$ to $90 \mathrm{~W}$; (b) CPL: $90 \mathrm{~W}$ to $60 \mathrm{~W}$.

2. Positive Damping Injecting and Conductance Injecting

From (25), (30) and (31), the convergence rate of $H_{\mathrm{P}}\left(x_{\mathrm{E}}\right)$ depends on $g_{\mathrm{a}}$ and $r_{\mathrm{a}}$, and impacts on the dynamic response of the $u_{\mathrm{C}}$. The dynamic responses of the $u_{\mathrm{C}}$ when the CPL steps from $60 \mathrm{~W}$ to $90 \mathrm{~W}$ and $90 \mathrm{~W}$ to $60 \mathrm{~W}$ at $0.5 \mathrm{~s}$ under different values of $g_{\mathrm{a}}$ and $r_{\mathrm{a}}\left(g_{\mathrm{a}}=1, r_{\mathrm{a}}=2.12 ; g_{\mathrm{a}}=2, r_{\mathrm{a}}=4.24 ; g_{\mathrm{a}}=3, r_{\mathrm{a}}=6.36 ; g_{\mathrm{a}}=4, r_{\mathrm{a}}=8.48 ; g_{\mathrm{a}}=5, r_{\mathrm{a}}=10.6\right)$ are shown in Figure 9.

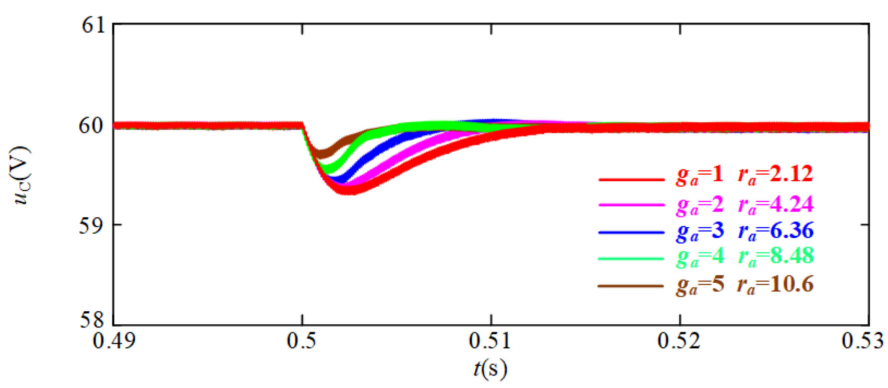

(a)

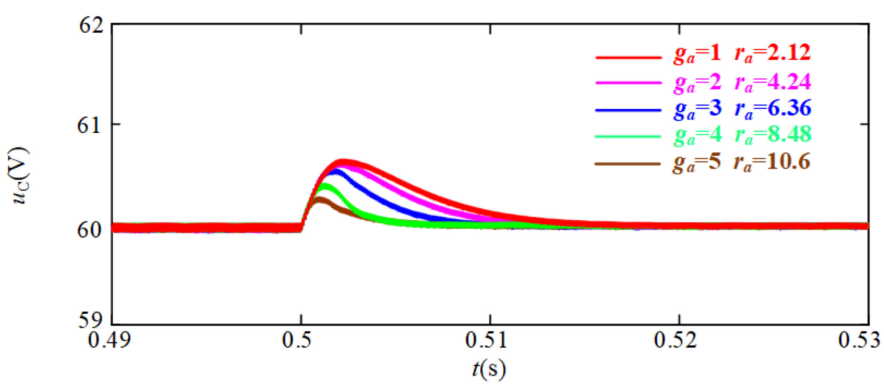

(b)

Figure 9. Simulated $u_{\mathrm{C}}$ responses of the different $g_{\mathrm{a}}$ and $r_{\mathrm{a}}$ when CPL steps up and down. (a) CPL: $60 \mathrm{~W}$ to $90 \mathrm{~W}$; (b) CPL: $90 \mathrm{~W}$ to $60 \mathrm{~W}$. 
It can be observed from Figure 9 that the larger $g_{\mathrm{a}}$ and $r_{\mathrm{a}}$ will lead to a faster convergence rate for $H_{\mathrm{P}}\left(x_{\mathrm{E}}\right)$, and the $u_{\mathrm{C}}$ can track the $U_{\mathrm{CD}}$ within a short transition while the voltage fluctuation peak is lower. Thus, the proper values of $g_{\mathrm{a}}$ and $r_{\mathrm{a}}$ should be selected to obtain a fast dynamic response of $u_{C}$ while avoiding a large voltage overshoot.

\section{Interconnection Injecting}

Figure 10 shows the simulation results of the output voltage dynamic response when the CPL steps from $60 \mathrm{~W}$ to $90 \mathrm{~W}$ and $90 \mathrm{~W}$ to $60 \mathrm{~W}$ at $0.5 \mathrm{~s}$ with different values of $j_{\mathrm{a}}$ $\left(j_{\mathrm{a}}=3,5,7,9\right.$ and 11$)$.

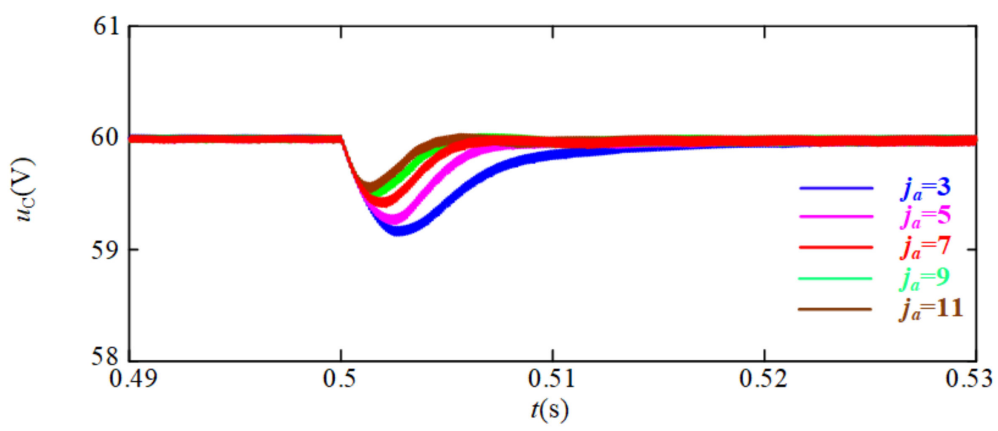

(a)

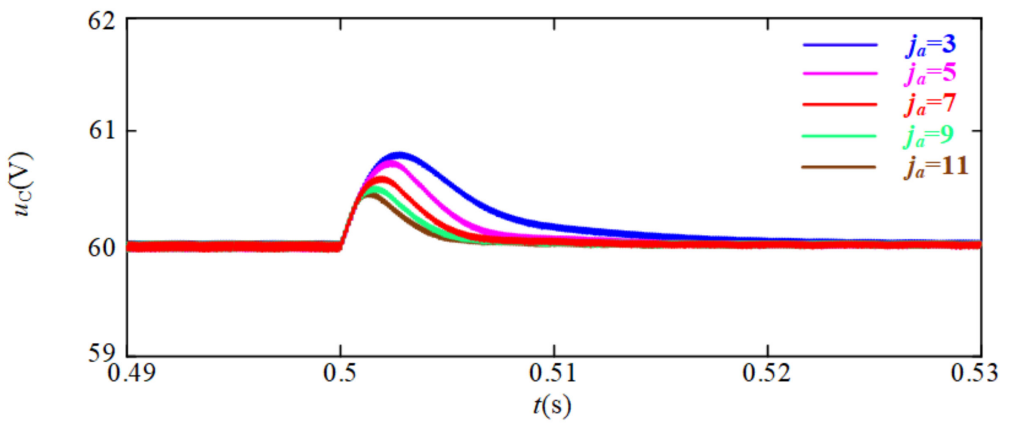

(b)

Figure 10. Simulated $u_{C}$ responses of the different $j_{a}$ when CPL steps up and down. (a) CPL: $60 \mathrm{~W}$ to $90 \mathrm{~W}$; (b) CPL: $90 \mathrm{~W}$ to $60 \mathrm{~W}$.

It is clearly observed in Figure 10 that a larger $j_{\mathrm{a}}$ will lead to a shorter settling time and a lower voltage fluctuation peak for the $U_{\mathrm{CD}}$ tracking. Thus, $j_{\mathrm{a}}$ can be selected at a larger value in order to obtain a better dynamic response of $u_{C}$.

In order to further verify the influence of control parameters on DDBC stability, and guide the selection of parameters, the phase portraits of DDBC using IPBC under different value of parameters are shown in Figures A1 and A2 (Appendix A). It can be observed that larger $g_{\mathrm{a}}, r_{\mathrm{a}}$, and $j_{\mathrm{a}}$ will lead to a larger unstable region. According to the influence of control parameters on dynamic response and stability, the $g_{\mathrm{a}}, r_{\mathrm{a}}$ and $j_{\mathrm{a}}$ can each be made a compromise choice. Therefore, $g_{\mathrm{a}}$ and $r_{\mathrm{a}}$ can be selected as 3 and 6.36, respectively, and $j_{\mathrm{a}}$ can be selected as 7; these parameters will be used in the following simulations and experiments.

Based on the selection of the above parameters, the phase portrait of DDBC by using IPBC as shown in Figure 11 is compared with Figure 4; the output voltage and inductor current can converge to the desired equilibrium point $P$ and realize the stable work of the DDBC. 


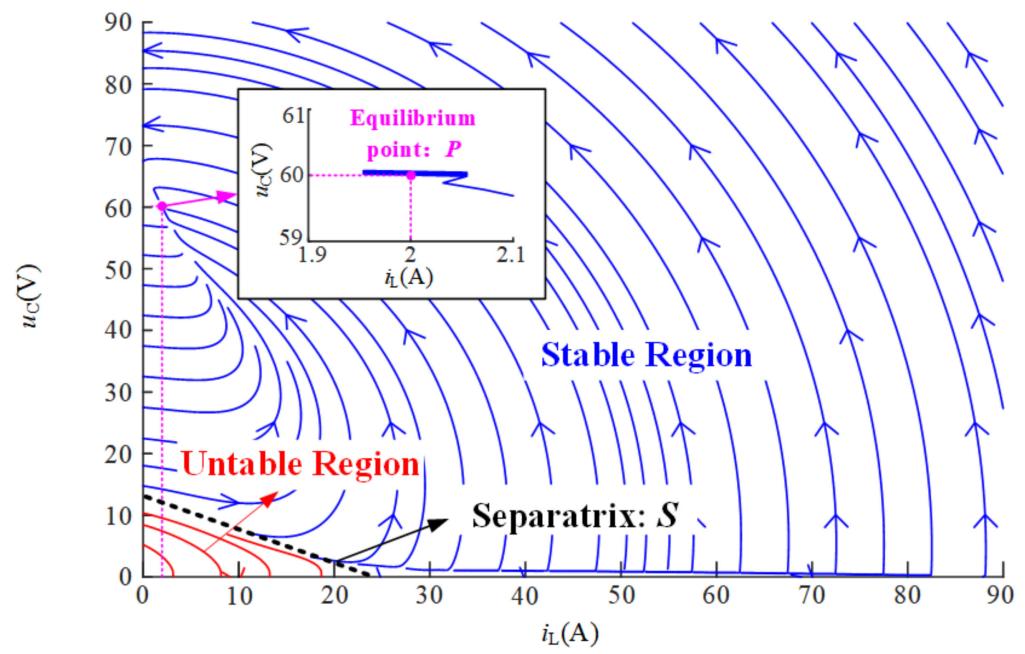

Figure 11. Phase portrait of DDBC by using IPBC when feeding CPL.

\subsubsection{Simulation Verification}

Simulations are carried out based on MATLAB/Simulink to validate the proposed control strategy. The simulation parameters are shown in Table 1 of DDBC with CPL, and used in the simulations for comparative purpose. To verify the advantages of the proposed control strategy, the IDA-PBC [28] and PBC [22] are implemented for the DDBC with the same simulation parameters. The $u_{C}$ is considered to operate into a steady state when it fluctuates at $U_{\mathrm{CD}} \pm 0.2 \mathrm{~V}$.

\section{Step Change in $u_{\mathrm{S}}$}

Figure 12 shows the simulation results of the output voltage when $u_{\mathrm{S}}$ steps from $30 \mathrm{~V}$ to $40 \mathrm{~V}$ at $0.5 \mathrm{~s}$ with different control strategies. The $u_{\mathrm{C}}$ has approximately $21 \mathrm{~V}$ deviation from the $U_{\mathrm{CD}}$ when the $\mathrm{PBC}$ is used, while the steady-state output voltage error is eliminated by using the proposed control strategy and IDA-PBC. Furthermore, the voltage overshoot of the proposed control strategy is less than $0.2 \mathrm{~V}$, significantly smaller than the IDA-PBC under the $u_{\mathrm{S}}$ steps, and it has the faster convergence rate for $U_{\mathrm{CD}}$.

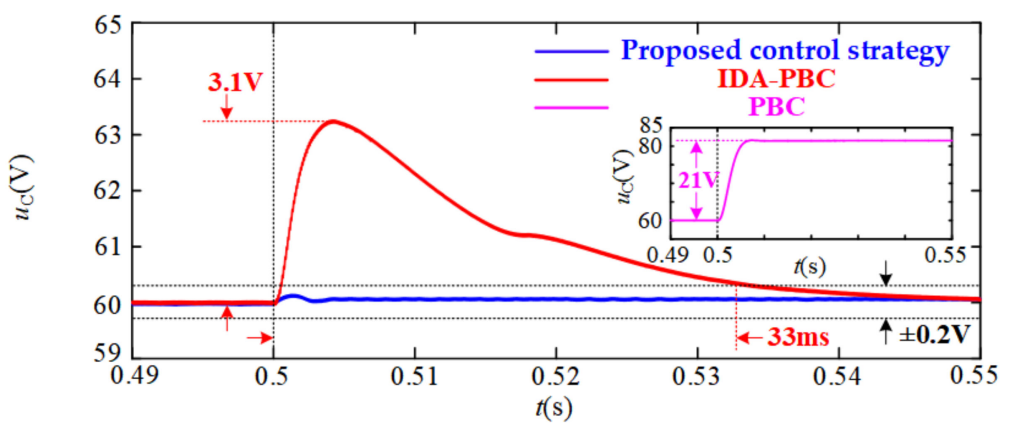

Figure 12. The simulation results of the different control strategies under input voltage mutation.

2. Step Change in $P_{\mathrm{CPL}}$

Figure 13 gives the comparison results of the output voltage when the CPL steps from $60 \mathrm{~W}$ to $90 \mathrm{~W}$ at $0.5 \mathrm{~s}$ and $90 \mathrm{~W}$ to $60 \mathrm{~W}$ at $1 \mathrm{~s}$ with different control strategies.

As shown in Figure 13, the output voltage performances of the proposed control strategy, IDA-PBC and PBC, can be obtained. Comparing the simulation results, the $u_{\mathrm{C}}$ has approximately $3.5 \mathrm{~V}$ deviation from the $U_{\mathrm{CD}}$ when the $\mathrm{PBC}$ is used, and the $\mathrm{PBC}$ cannot realize the operating point tracking when the CPL steps. Meanwhile, the steady-state output voltage error is eliminated by using the proposed control strategy and IDA-PBC, and the voltage overshoot of proposed control strategy is significantly smaller than the 
IDA-PBC. Moreover, the $u_{\mathrm{C}}$ has the faster dynamic performance by using the proposed control strategy, and it can track the $U_{\mathrm{CD}}$ accurately within a very short transition, which is much better than the IDA-PBC. Therefore, the proposed control strategy can realize the faster convergence rate of operating point tracking when the CPL steps.

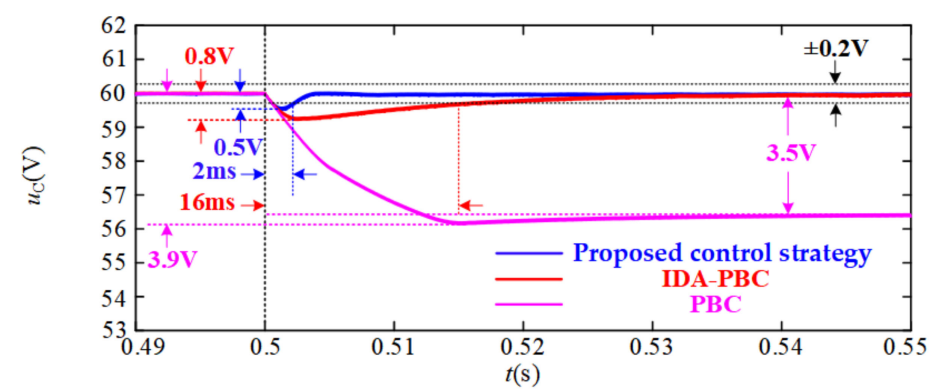

(a)

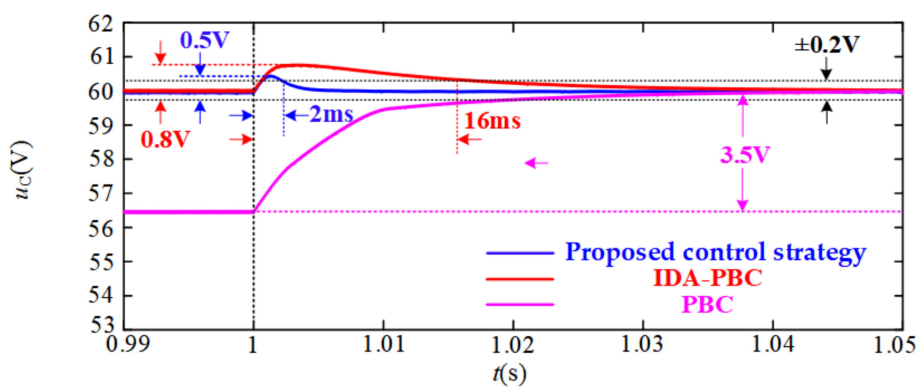

(b)

Figure 13. The simulation results of the different control strategies under CPL steps. (a) $60 \mathrm{~W}$ to 90 $\mathrm{W}$ at $0.5 \mathrm{~s}$; (b) $90 \mathrm{~W}$ to $60 \mathrm{~W}$ at $1 \mathrm{~s}$.

Based on the simulation results of Tables 2 and 3, the proposed control strategy can ensure the faster dynamic performance and stability of DDBC, and realize the accurate output voltage and operating point tracking.

Table 2. Simulation results for $u_{\mathrm{C}}$ of DDBC under different control strategies and input voltage disturbances.

\begin{tabular}{ccccc}
\hline Input Voltage Disturbance & Control Strategy & $\begin{array}{c}\text { Fluctuation } \\
\text { Peak Value } \\
\text { of } u_{\mathrm{C}}(\mathrm{V})\end{array}$ & $\begin{array}{c}\text { Transient Time } \\
\text { of } u_{\mathrm{C}}(\mathrm{ms})\end{array}$ & Steady State Error $(\mathrm{V})$ \\
\hline \multirow{3}{*}{$30 \mathrm{~V}$ to $40 \mathrm{~V}$} & Proposed control strategy & $\approx 0$ & $\approx 0$ & $\approx 0$ \\
& PBC [2] & 21 & - & 21 \\
& IDA-PBC [28] & 3.1 & 33 & $\approx 0$ \\
\hline
\end{tabular}

Table 3. Simulation results for $u_{\mathrm{C}}$ of DDBC under different control strategies and CPL disturbances.

\begin{tabular}{|c|c|c|c|c|}
\hline $\begin{array}{c}\text { CPL } \\
\text { Disturbance }\end{array}$ & Control Strategy & $\begin{array}{c}\text { Fluctuation } \\
\text { Peak Value } \\
\text { of } u_{\mathrm{C}}(\mathrm{V})\end{array}$ & $\begin{array}{l}\text { Transient Time } \\
\text { of } u_{\mathrm{C}}(\mathrm{ms})\end{array}$ & Steady State Error (V) \\
\hline \multirow{3}{*}{$60 \mathrm{~W}$ to $90 \mathrm{~W}$} & $\begin{array}{c}\text { Proposed control } \\
\text { strategy }\end{array}$ & 0.5 & 2 & $\approx 0$ \\
\hline & PBC [22] & 3.9 & - & 3.5 \\
\hline & IDA-PBC [28] & 0.8 & 16 & $\approx 0$ \\
\hline \multirow{3}{*}{$90 \mathrm{~W}$ to $60 \mathrm{~W}$} & $\begin{array}{c}\text { Proposed control } \\
\text { strategy }\end{array}$ & 0.5 & 2 & $\approx 0$ \\
\hline & PBC [22] & 3.5 & - & 3.5 \\
\hline & IDA-PBC [28] & 0.8 & 16 & $\approx 0$ \\
\hline
\end{tabular}




\subsection{Experimental Results}

The experimental system setup is shown in Figure 14, and the experimental parameters are the same as Table 1. It consists of a boost converter, a DC source, an oscilloscope, and a DC electronic load which is used to emulate the CPL. The $u_{C}$ of the DDBC is considered to enter a steady state when the output voltage fluctuates at $U_{\mathrm{CD}} \pm 1 \mathrm{~V}$.

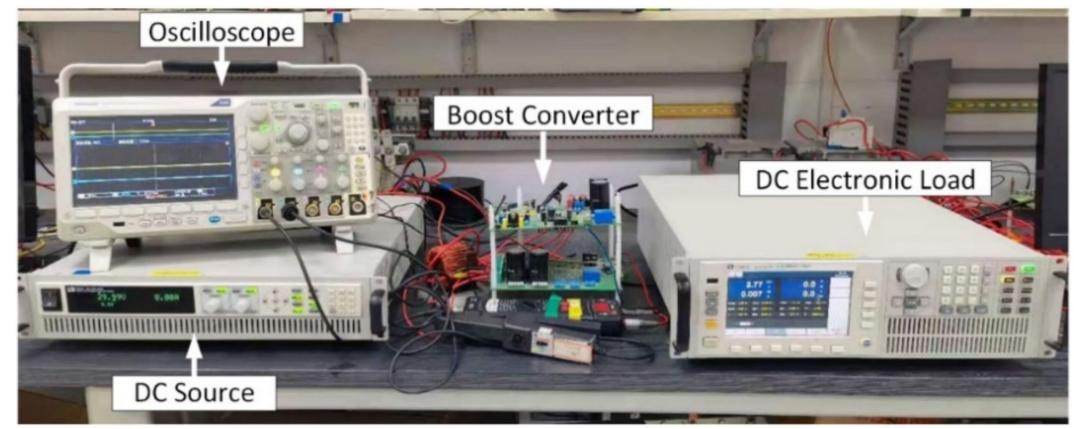

Figure 14. Experimental system setup.

\section{Step Change in $u_{\mathrm{S}}$}

The impact of the $u_{\mathrm{S}}$ steps is shown in Figure 15. In Figure 15a, the $u_{\mathrm{C}}$ has little or no overshoot, and quickly tracks the $U_{\mathrm{CD}}$ when the $u_{\mathrm{S}}$ steps from $30 \mathrm{~V}$ to $40 \mathrm{~V}$ by using the proposed strategy. In Figure 15b,c, the output voltage overshoots are much larger than the proposed control strategy, and the $u_{\mathrm{C}}$ of $\mathrm{PBC}$ has approximately $23 \mathrm{~V}$ deviation from the $U_{\mathrm{CD}}$ when the $\mathrm{PBC}$ is used. Therefore, compared to other control strategies, the proposed control strategy can track the $U_{\mathrm{CD}}$ within a very short transition, and has better dynamic response when the $u_{\mathrm{S}}$ changes.

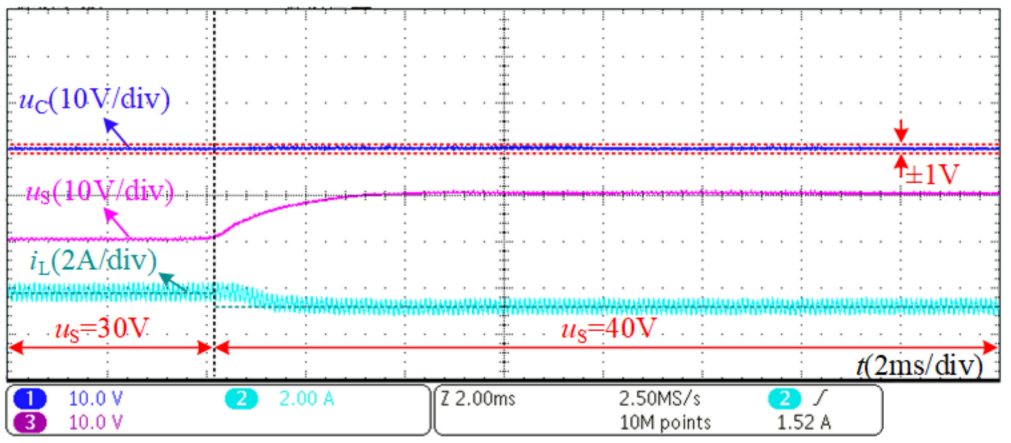

(a)

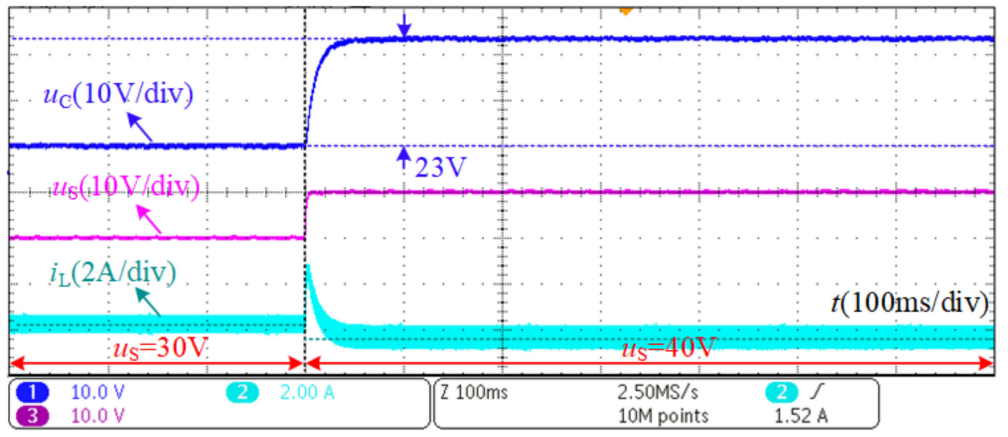

(b)

Figure 15. Cont. 


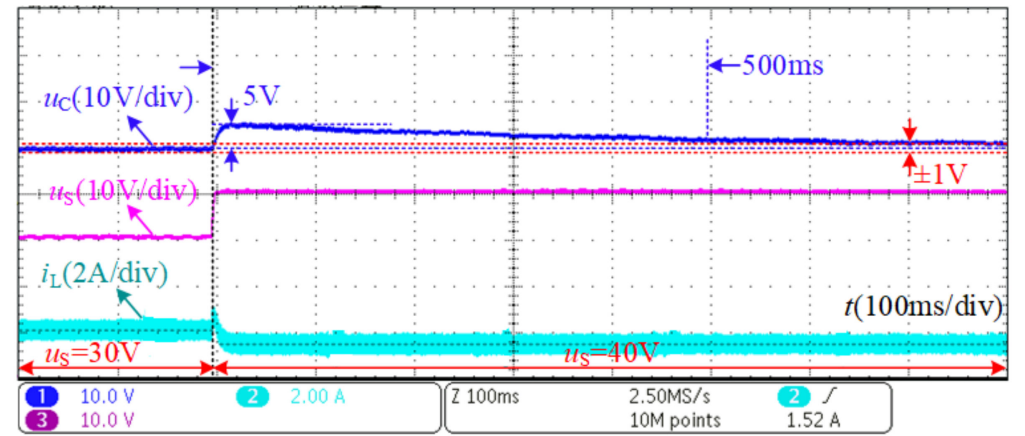

(c)

Figure 15. $u_{\mathrm{C}}$ and $i_{\mathrm{L}}$ experiment results of the different control strategies when $u_{\mathrm{S}}$ steps from $30 \mathrm{~V}$ to 40 V. (a) The proposed control strategy; (b) PBC; (c) IDA-PBC.

\section{Step Change in $P_{\mathrm{CPL}}$}

As shown in Figure 16a, when the CPL steps from $60 \mathrm{~W}$ to $90 \mathrm{~W}$ and $90 \mathrm{~W}$ back to $60 \mathrm{~W}$, the output voltage has the overshoot below $1 \mathrm{~V}$ and then drops back to $U_{\mathrm{CD}}$ by using the proposed strategy. However, in Figure 16b, the PBC cannot track the desired value and has approximately $8 \mathrm{~V}$ deviation from the $U_{\mathrm{CD}}$ under the CPL steps. In Figure 16c, the overshoot of output voltage is much larger than the proposed control strategy, and the settling time is more than 350 milliseconds using IDA-PBC. Thus, the proposed control strategy can realize the faster convergence rate of $u_{C}$ and ensure the operating point tracking when the CPL changes significantly.
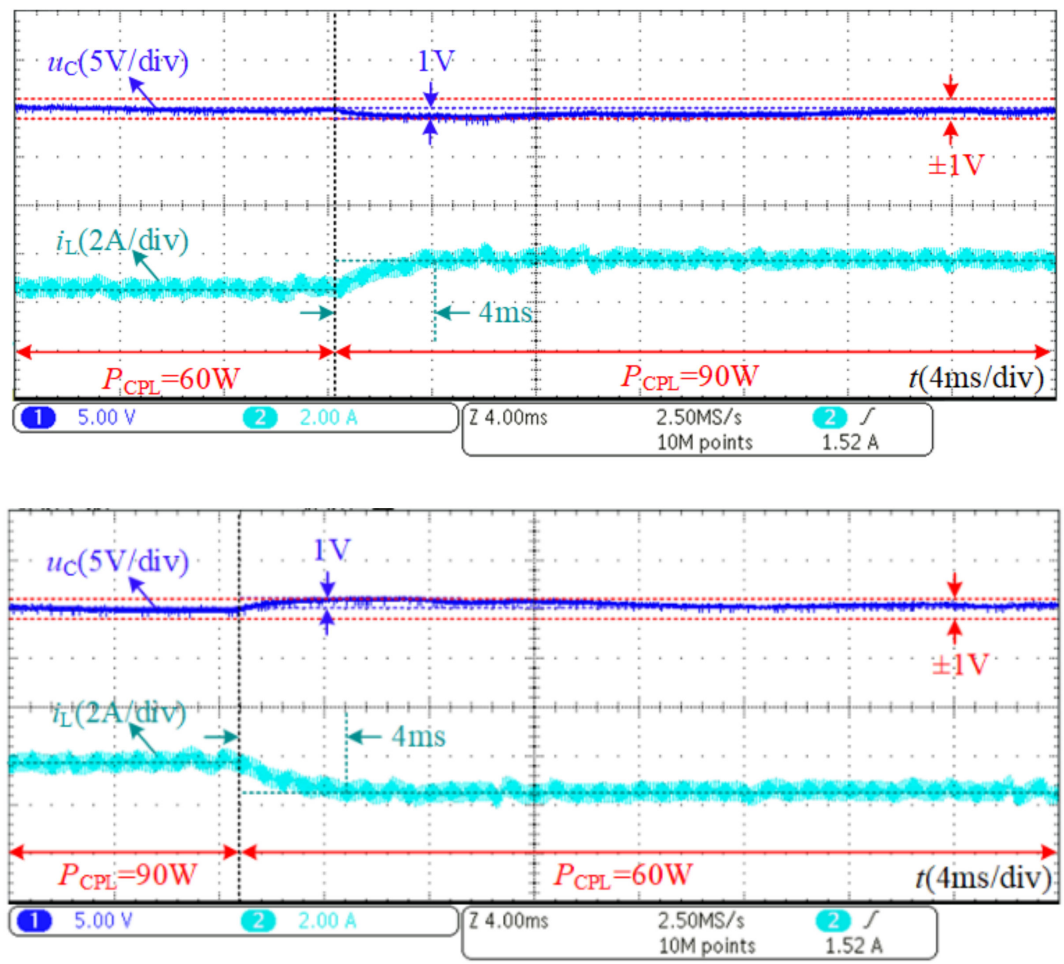

(a)

Figure 16. Cont. 

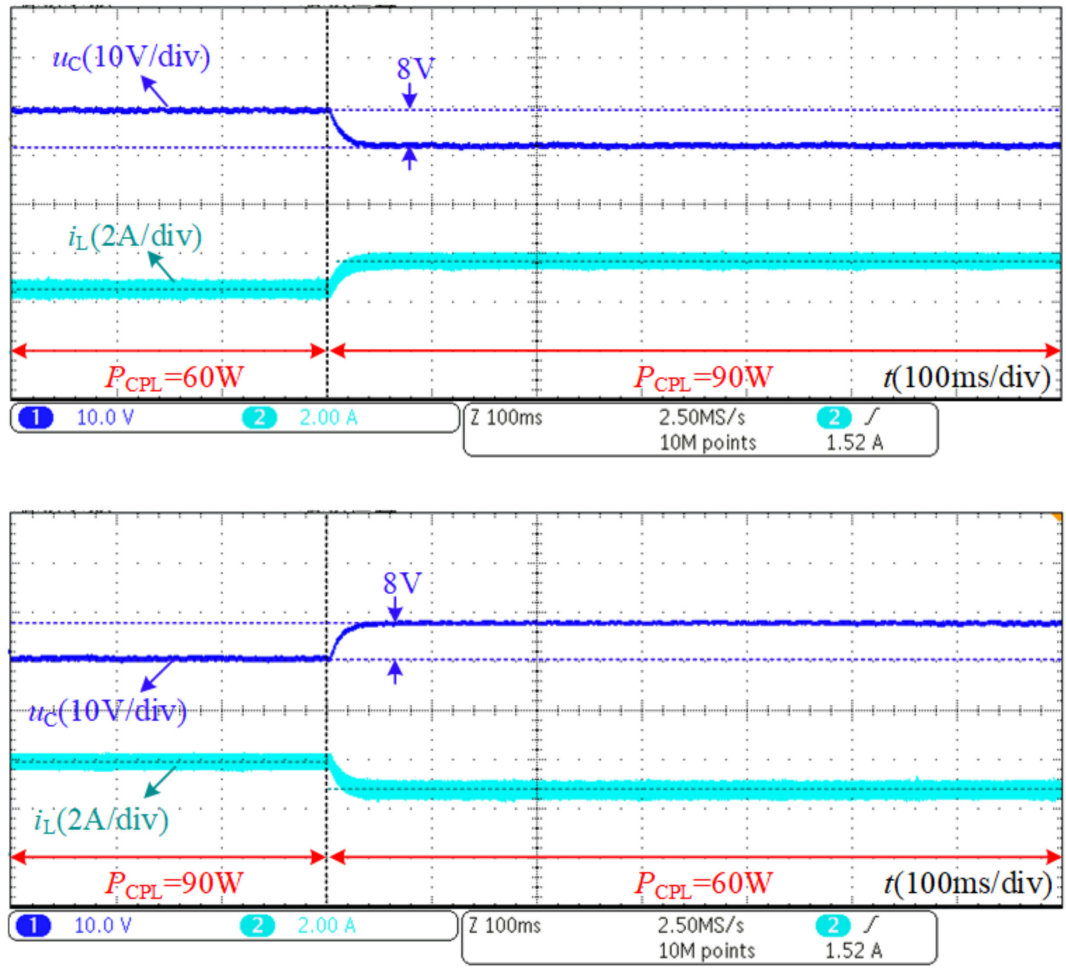

(b)
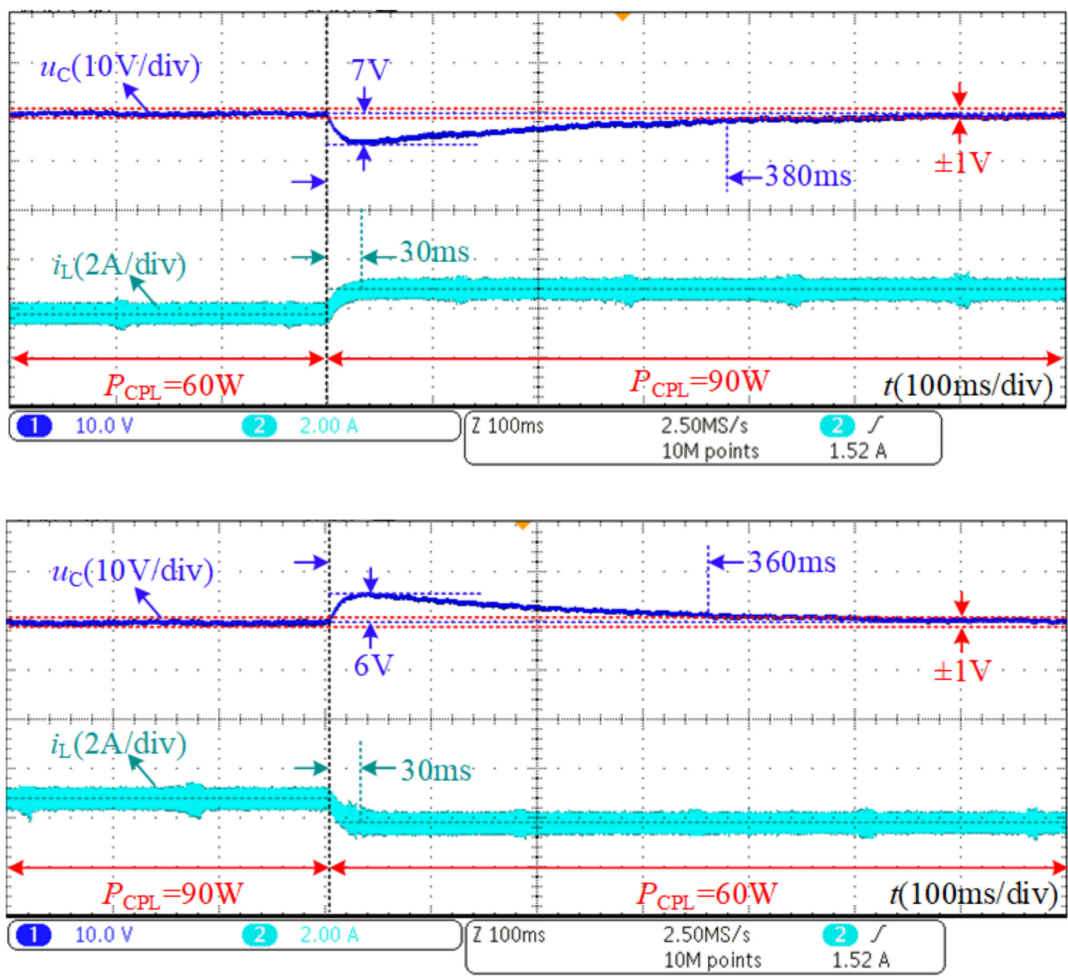

(c)

Figure 16. $u_{\mathrm{C}}$ and $i_{\mathrm{L}}$ experiment results of the different control strategies when CPL steps up and down (60 W to $90 \mathrm{~W}$ and $90 \mathrm{~W}$ to $60 \mathrm{~W}$, respectively). (a) The proposed control strategy; (b) PBC; (c) IDA-PBC 
Based on the experiment results from Tables 4 and 5, the proposed control strategy can ensure DDBC stability with a fast dynamic performance, and realize the accurate output voltage and operating point tracking under various disturbances. The dynamic response and overshoot for experimental cases are slightly slower and larger than the corresponding simulation results. This is acceptable, as in the simulation studies the ideal CPL with the step change is used, whereas in the experimental tests, the $u_{\mathrm{S}}$ and CPL steps are restricted by their controller bandwidth. Moreover, the experimental results suffer from real-life system conditions such as Electro-Magnetic Interference (EMI), noise, delays, and various uncertainties disturbances which are not considered in the simulations.

Table 4. Experimental results for $u_{\mathrm{C}}$ of DDBC under different control strategies and input voltage disturbances.

\begin{tabular}{ccccc}
\hline $\begin{array}{c}\text { Input Voltage } \\
\text { Disturbance }\end{array}$ & Control Strategy & $\begin{array}{c}\text { Fluctuation } \\
\text { Peak Value } \\
\text { of } u_{\mathrm{C}}(\mathrm{V})\end{array}$ & $\begin{array}{c}\text { Transient Time } \\
\text { of } \boldsymbol{u}_{\mathrm{C}}(\mathbf{m s})\end{array}$ & Steady State Error $(\mathrm{V})$ \\
\hline & Proposed control strategy & $\approx 0$ & $\approx 0$ & $\approx 0$ \\
$30 \mathrm{~V}$ to $40 \mathrm{~V}$ & PBC [22] & 23 & - & 23 \\
& IDA-PBC [28] & 5 & 500 & $\approx 0$ \\
\hline
\end{tabular}

Table 5. Experimental results for $u_{C}$ of DDBC under different control strategies and CPL disturbances.

\begin{tabular}{|c|c|c|c|c|}
\hline $\begin{array}{c}\text { CPL } \\
\text { Disturbance }\end{array}$ & Control Strategy & $\begin{array}{l}\text { Fluctuation } \\
\text { Peak Value } \\
\text { of } u_{\mathrm{C}}(\mathrm{V})\end{array}$ & $\begin{array}{l}\text { Transient Time } \\
\text { of } u_{\mathrm{C}}(\mathrm{ms})\end{array}$ & Steady State Error (V) \\
\hline \multirow{3}{*}{$60 \mathrm{~W}$ to $90 \mathrm{~W}$} & Proposed control strategy & $<1$ & $\approx 0$ & $\approx 0$ \\
\hline & PBC [22] & 8 & - & 8 \\
\hline & IDA-PBC [28] & 7 & 380 & $\approx 0$ \\
\hline \multirow{3}{*}{$90 \mathrm{~W}$ to $60 \mathrm{~W}$} & Proposed control strategy & $<1$ & $\approx 0$ & $\approx 0$ \\
\hline & PBC [22] & 8 & - & 8 \\
\hline & IDA-PBC [28] & 6 & 360 & $\approx 0$ \\
\hline
\end{tabular}

\section{Conclusions}

The instability problem caused by the CPL for DDBC is addressed in this paper. To solve this problem, the stability of DDBC with CPL is studied based on passivity, and the nonlinear control strategy which consists of the IPBC and NPO is proposed. First, the IPBC is studied using damping and interconnection injecting based on the PCHD model and the parameters of IPBC are designed from the perspective of energy conservation. From the phase portraits of DDBC, the stability of DDBC is realized by IPBC. Second, the adaptability of the DDBC is improved as the CPL and input voltage change through the design of NPO. The NPO with large $\gamma$ is employed to estimate load power with a fast dynamic response to ensure the accurate desired operating point tracking. Meanwhile, extensive numerical simulation and experimental results are given to verify the validity of the proposed control strategy. Under different large disturbances, both results indicate that the output voltage has the voltage overshoot below $1 \mathrm{~V}$ and can accurately track the $U_{\mathrm{CD}}$ within 10 milliseconds by using the proposed strategy, which are significantly better than PBC and IDA-PBC. Furthermore, the consistency of simulation and experimental results is validated. Finally, the proposed control algorithm is also applicable to other DDC topologies.

Author Contributions: Conceptualization, J.W.; methodology, M.W. and F.T.; validation, M.W. and F.T.; formal analysis, M.W. and J.N.; investigation, M.W. and Y.Z.; writing-review and editing, M.W. and F.T.; supervision, X.W. All authors have read and agreed to the published version of the manuscript.

Funding: This research was funded by National Natural Science Foundation, grant number 51777012, Natural Science Foundation of Beijing-Education Committee Joint Funding Project, grant number 
KZ201911232045, and Science and technology project of China Southern Power Grid Company Limited, grant number 090000KK52190002.

Institutional Review Board Statement: Not applicable.

Informed Consent Statement: Not applicable.

Data Availability Statement: The data presented in this study are available on request from the corresponding author. The data are not publicly available as the data also forms part of an ongoing study.

Conflicts of Interest: The authors declare no conflict of interest.

\section{Appendix A}

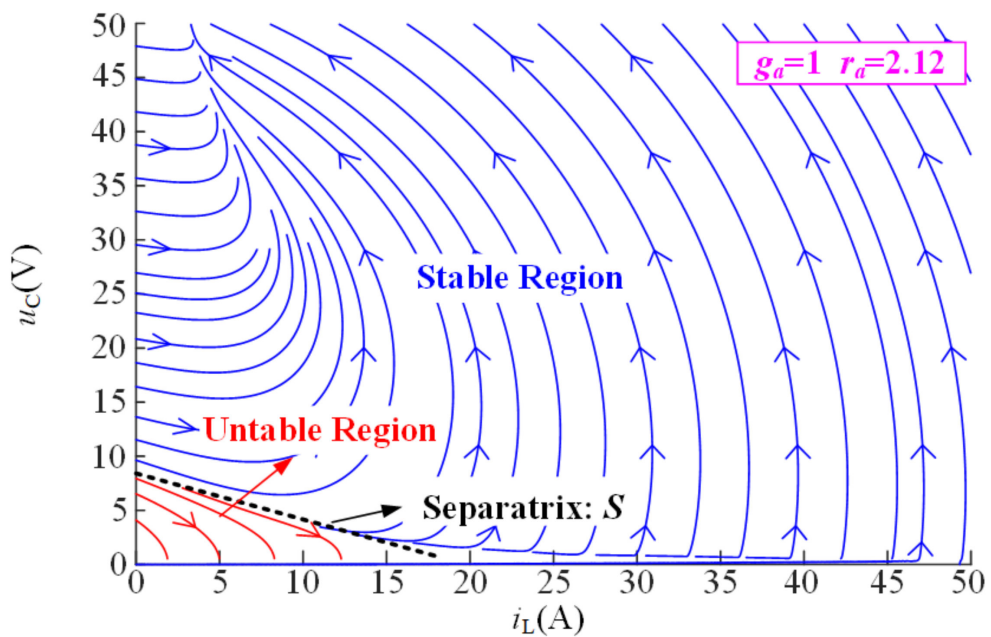

(a)

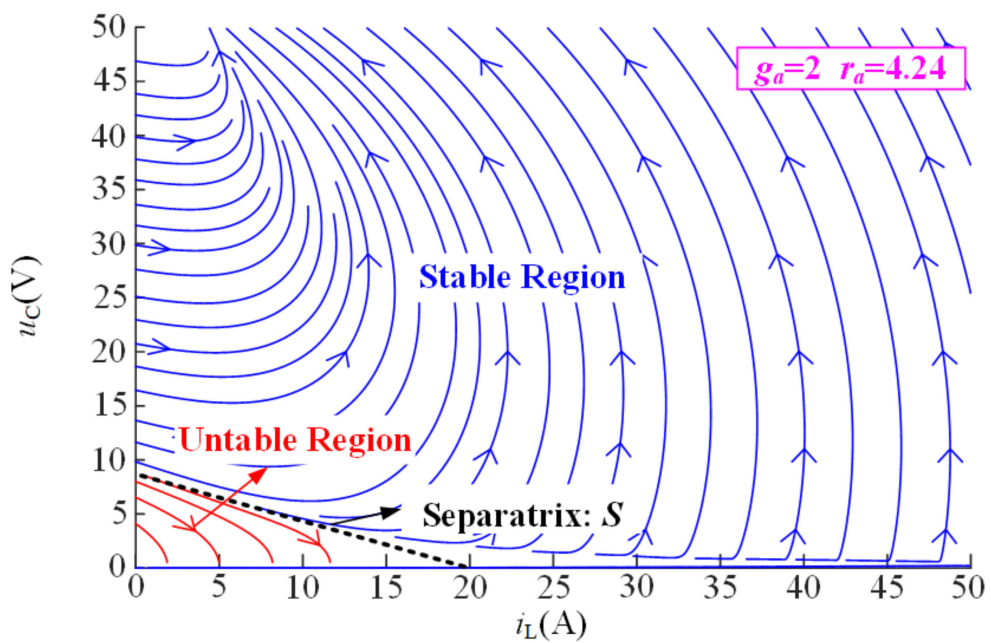

(b)

Figure A1. Cont. 


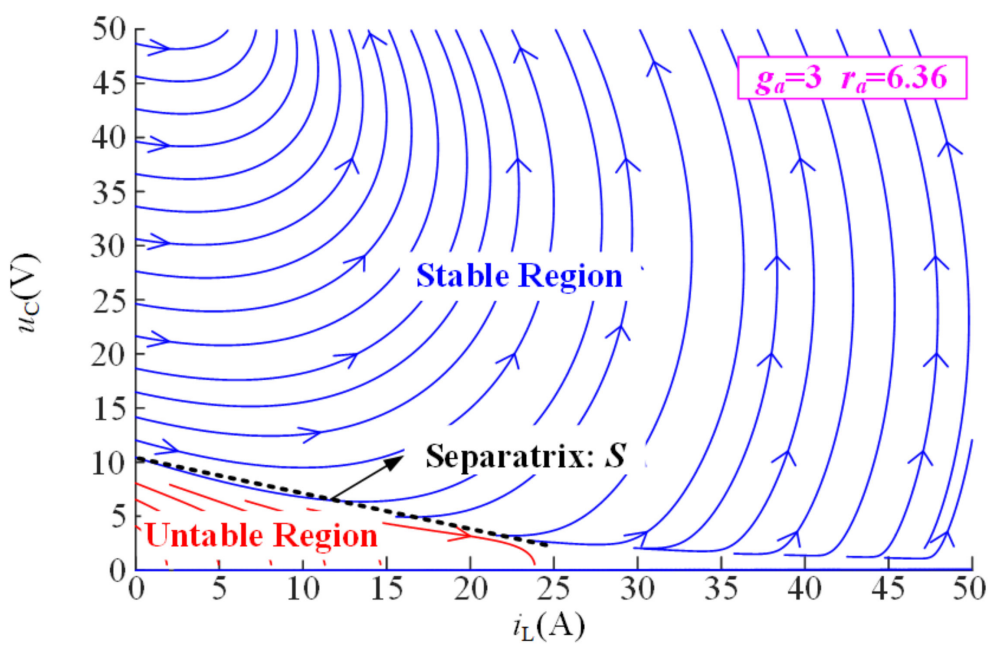

(c)

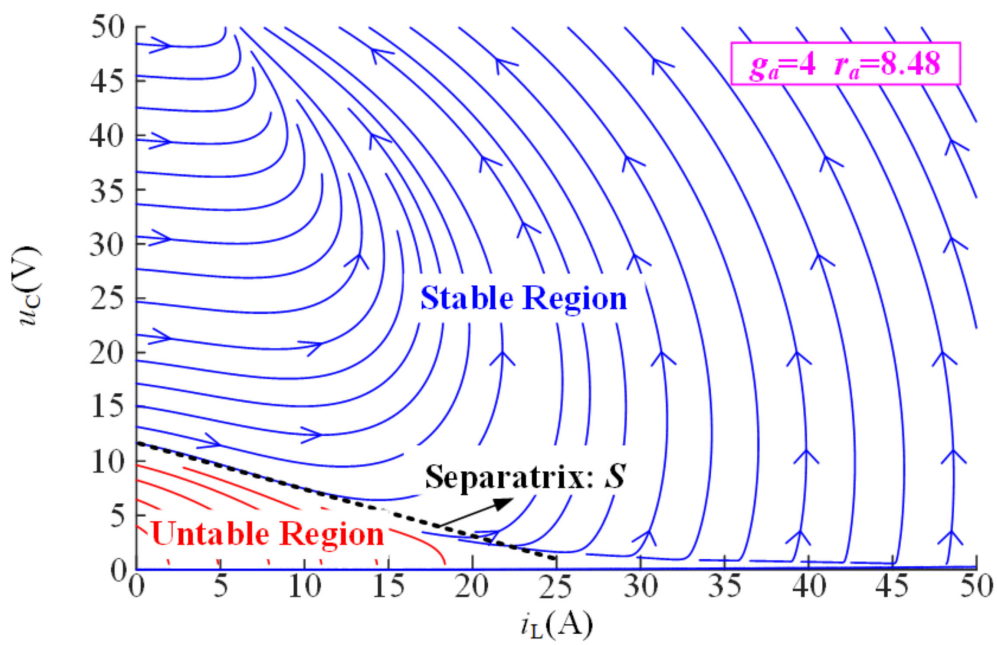

(d)

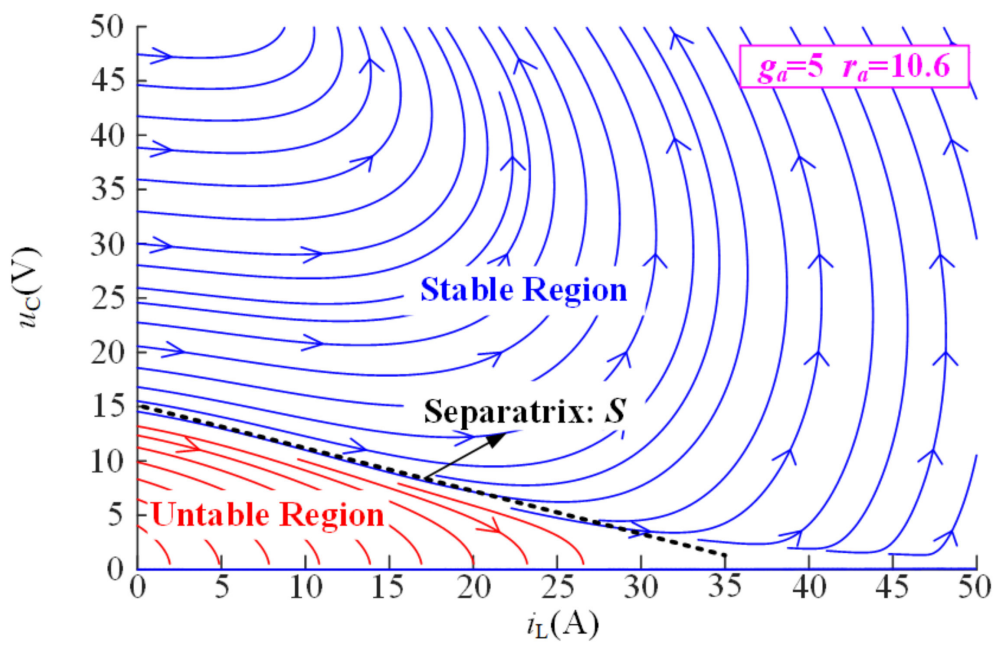

(e)

Figure A1. Phase portraits of DDBC with different $g_{\mathrm{a}}$ and $r_{\mathrm{a}}$ when feeding CPL. (a) $g_{\mathrm{a}}=1$ and $r_{\mathrm{a}}=2.12 ;(\mathbf{b}) g_{\mathrm{a}}=2$ and $r_{\mathrm{a}}=4.24 ;$ (c) $g_{\mathrm{a}}=3$ and $r_{\mathrm{a}}=6.36$; (d) $g_{\mathrm{a}}=4$ and $r_{\mathrm{a}}=8.48 ;(\mathbf{e}) g_{\mathrm{a}}=5$ and $r_{\mathrm{a}}=10.6$. 


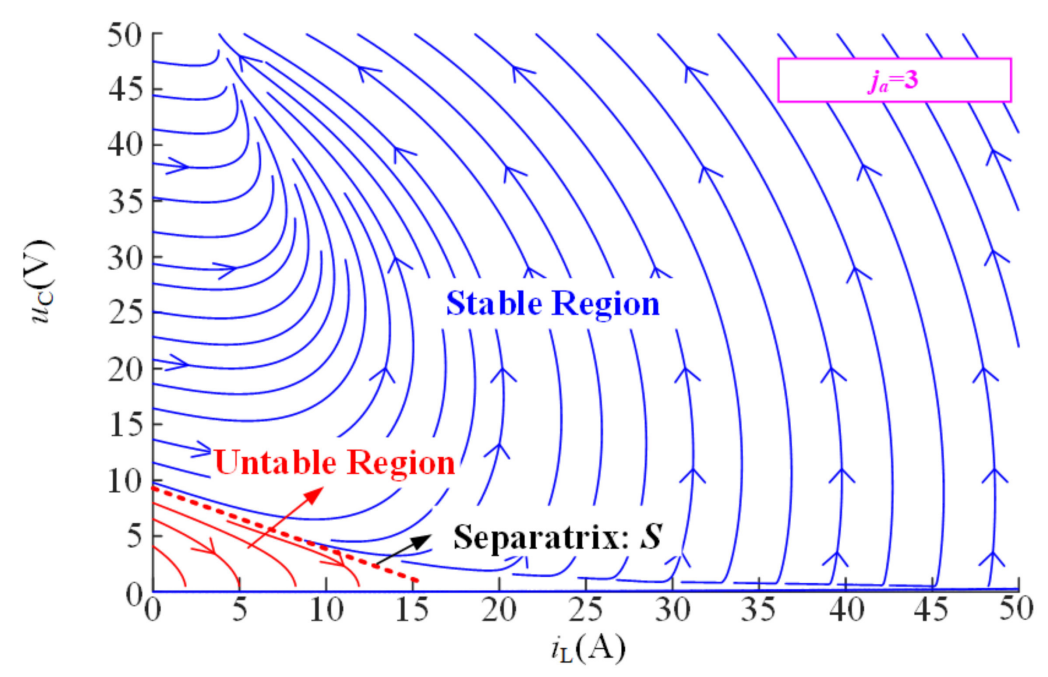

(a)

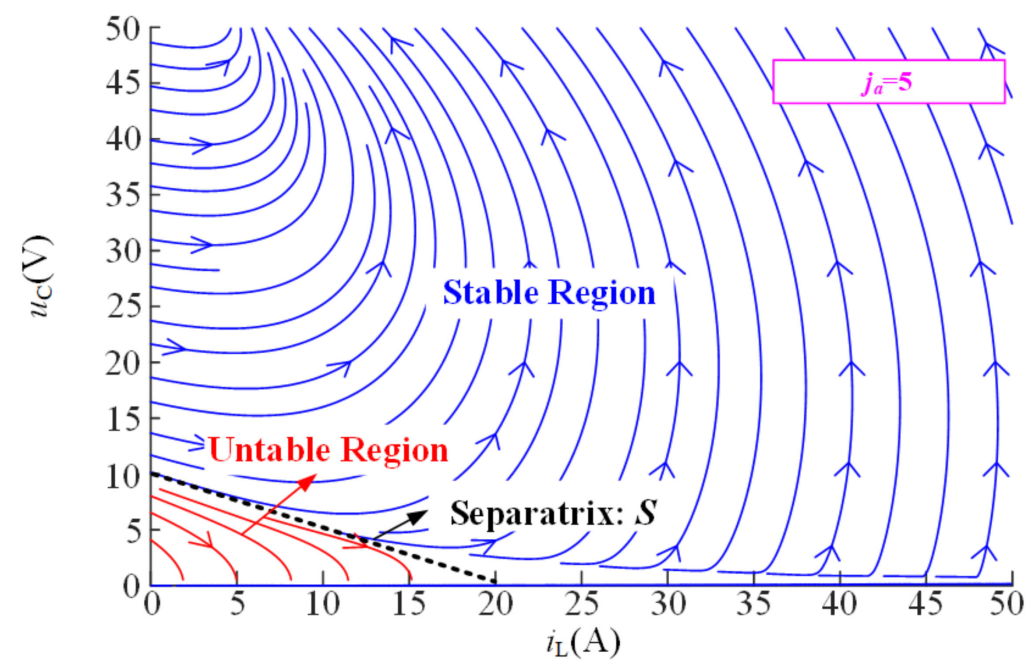

(b)

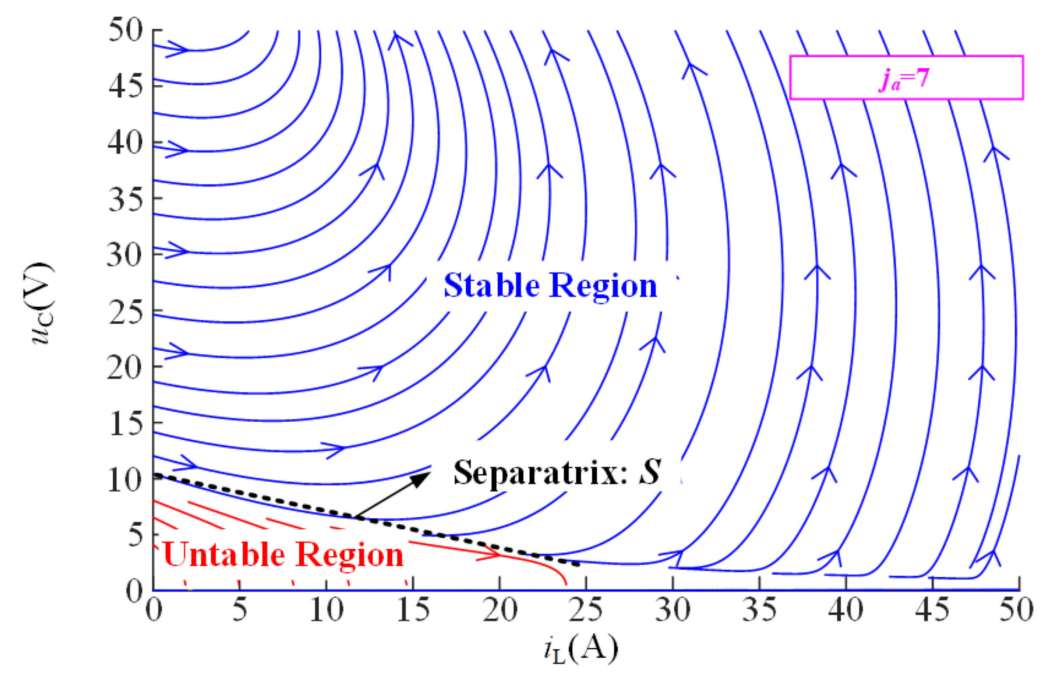

(c)

Figure A2. Cont. 


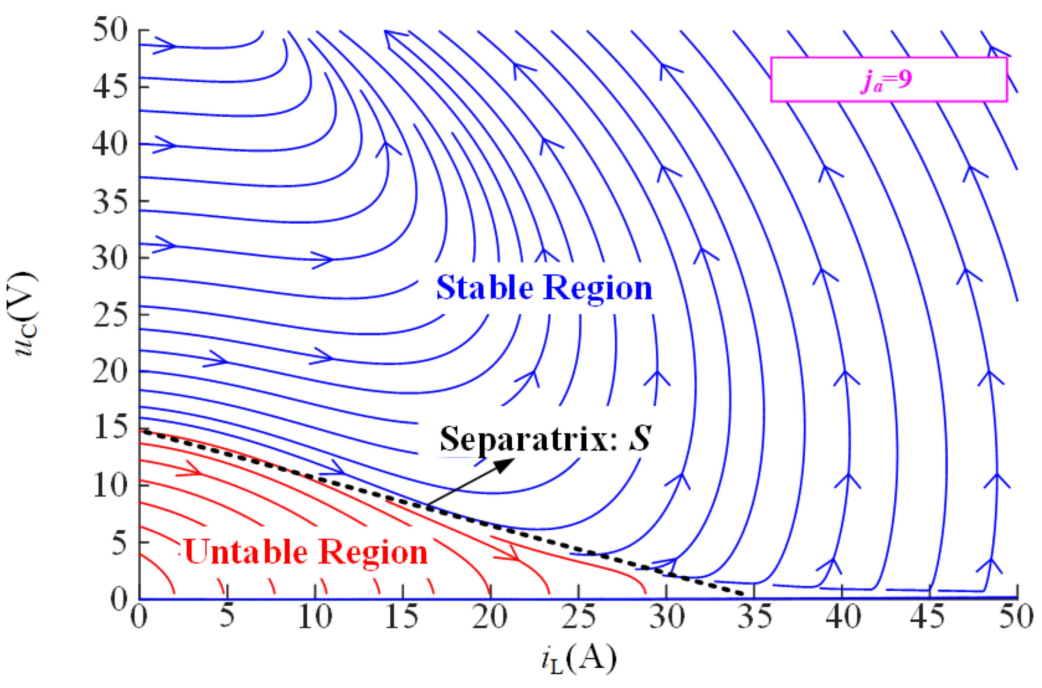

(d)

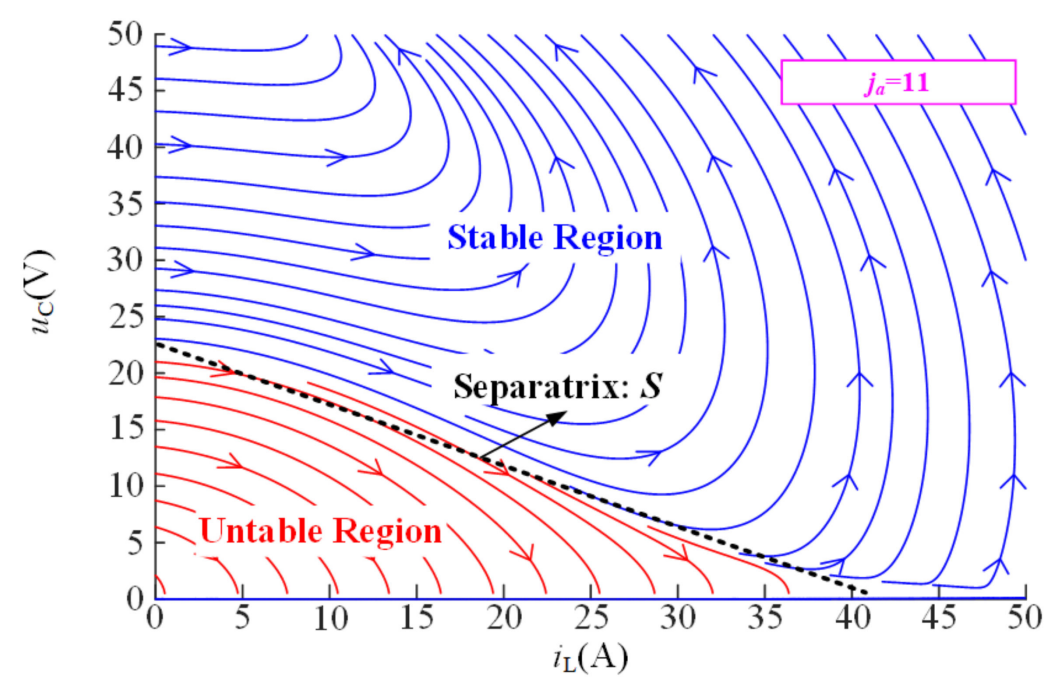

(e)

Figure A2. Phase portraits of DDBC with different $j_{\mathrm{a}}$ when feeding CPL. (a) $j_{\mathrm{a}}=3 ;$ (b) $j_{\mathrm{a}}=5 ;$ (c) $j_{\mathrm{a}}=7$; (d) $j_{\mathrm{a}}=9 ;(\mathbf{e}) j_{\mathrm{a}}=11$.

\section{References}

1. Hamzeh, M.; Ghazanfari, A.; Mohamed, Y.A.-R.I.; Karimi, Y. Modeling and Design of an Oscillatory Current-Sharing Control Strategy in DC Microgrids. IEEE Trans. Ind. Electron. 2015, 62, 6647-6657. [CrossRef]

2. Huang, P.; Liu, P.; Xiao, W.; El Moursi, M.S. A novel droop-based average voltage sharing control strategy for DC mi-crogrids. IEEE Trans. Smart Grid 2015, 6, 1096-1106. [CrossRef]

3. Kolluri, R.R.; Mareels, I.; De Hoog, J. Controlling DC microgrids in communities, buildings and data centers. IET Smart Grid 2020, 3, 376-384. [CrossRef]

4. Dragičević, T.; Lu, X.; Vasquez, J.C.; Guerrero, J.M. DC Microgrids-Part I: A Review of Control Strategies and Stabiliza-tion Techniques. IEEE Trans. Power Electron. 2016, 31, 4876-4891.

5. Su, M.; Liu, Z.J.; Sun, Y.; Han, H.; Hou, X. Stability analysis and stabilization methods of DC microgrid with multiple parallelconnected DC-DC converters Loaded by CPLs. IEEE Trans. Smart Grid 2018, 9, 132-142. [CrossRef]

6. Farsizadeh, H.; Gheisarnejad, M.; Mosayebi, M.; Rafiei, M.; Khooban, M.H. An Intelligent and Fast Controller for DC/DC Converter Feeding CPL in a DC Microgrid. IEEE Trans. Circuits Syst. II Express Briefs 2020, 67, 1104-1108. [CrossRef]

7. Hamidi, S.A.; Nasiri, A. Stability Analysis of a DC-DC Converter for Battery Energy Storage System Feeding CPL. In Proceedings of the 2015 IEEE International Telecommunications Energy Conference (INTELEC), Osaka, Japan, 18-22 October 2015; pp. 1-5.

8. El Aroudi, A.; Haroun, R.; Al-Numay, M.S.; Calvente, J.; Giral, R. Fast-Scale Stability Analysis of a DC-DC Boost Converter With a Constant Power Load. IEEE J. Emerg. Sel. Top. Power Electron. 2021, 9, 549-558. [CrossRef] 
9. Lu, X.; Sun, K.; Guerrero, J.M.; Vasquez, J.C.; Huang, L.; Wang, J. Stability Enhancement Based on Virtual Impedance for DC Microgrids with Constant Power Loads. IEEE Trans. Smart Grid 2015, 6, 2770-2783. [CrossRef]

10. Azizi, A.; Hamzeh, M. Stability Analysis of a DC Microgrid With Constant Power Loads Using Small-Signal Equivalent Circuit. In Proceedings of the 2020 11th Power Electronics, Drive Systems, and Technologies Conference (PEDSTC), Tehran, Iran, 4-6 February 2020; pp. 1-6.

11. Liu, S.; Zhu, W.; Cheng, Y.; Xing, B. Modeling and Small-Signal Stability Analysis of an Islanded DC Microgrid with Dynamic Loads. In Proceedings of the 2015 IEEE 15th International Conference on Environment and Electrical Engineering (EEEIC), Rome, Italy, 10-13 June 2015; pp. 866-871.

12. Yue, X.; Wang, X.; Blaabjerg, F. Review of Small-Signal Modeling Methods Including Frequency-Coupling Dynamics of Power Converters. IEEE Trans. Power Electron. 2019, 34, 3313-3328. [CrossRef]

13. Tu, G.; Li, Y.; Xiang, J. A nonlinear boundary controller for buck converters feeding constant-power loads. In Proceedings of the 2017 36th Chinese Control Conference (CCC), Dalian, China, 26-28 July 2017; pp. 698-703.

14. Bacha, S.; Munteanu, I.; Bratcu, A.I. Power Electronic Converters Modeling and Control; Springer: London, UK, 2014.

15. Jiuhe, W. Advanced Nonlinear Control Theory and Application; Science Press: Beijing, China, 2011.

16. Zhaohui, G.; Hui, L.; Xiaobin, Z. Exact Linearization and Optimal Tracking Control of Boost Converter with Constant Power Loads. Proc. CSEE 2007, 27, 70-75. (In Chinese)

17. Arora, S.; Balsara, P.T.; Bhatia, D.K. Input-Output Linearization of a Boost Converter with Mixed Load (Constant Voltage Load and Constant Power Load). IEEE Trans. Power Electron. 2018, 34, 815-825. [CrossRef]

18. Jingqing, H. Active Disturbance Rejection Control Technique-The Technique for Estimating and Compensating the Uncer-Tainties; National Defense Industry Press: Beijing, China, 2008.

19. Ahmad, S.; Ahmad, A. Active disturbance rejection control of DC-DC boost converter: A review with modifications for improved performance. IET Power Electron. 2019, 12, 2095-2107. [CrossRef]

20. Trevino, B.A.M.; El Aroudi, A.; Vidal-Idiarte, E.; Cid-Pastor, A.; Martinez-Salamero, L. Sliding-mode control of a boost converter under constant power loading conditions. IET Power Electron. 2019, 12, 521-529. [CrossRef]

21. Wu, J.; Lu, Y. Adaptive Backstepping Sliding Mode Control for Boost Converter with Constant Power Load. IEEE Access 2019, 7, 50797-50807. [CrossRef]

22. Ortega, R.; Loría, A.; Nicklasson, P.J.; Sira-Ramírez, H. Passivity-Based Control of Euler-Lagrange Systems; Springer: London, UK, 1998.

23. Salimi, M.; Eghlim, A.L. Passivity-Based Control of the DC-DC buck Converters in High-Power Applications. In Proceedings of the TENCON 2014-2014 IEEE Region 10 Conference, Bangkok, Thailand, 22-25 October 2014; pp. 1-6.

24. Linares-Flores, J.; Barahona-Avalos, J.L.; Sira-Ramirez, H.; Contreras-Ordaz, M.A. Robust Passivity-Based Control of a BuckBoost-Converter/DC-Motor System: An Active Disturbance Rejection Approach. IEEE Trans. Ind. Appl. 2012, 48, $2362-2371$. [CrossRef]

25. Hernández-Márquez, E.; Silva-Ortigoza, R.; García-Sánchez, J.R.; Marcelino-Aranda, M.; Saldaña-González, G. A DC/DC Buck-Boost Converter-Inverter-DC Motor System: Sensorless Passivity-Based Control. IEEE Access 2018, 6, 31486-31492. [CrossRef]

26. Wang, B.; Feng, H.; Bingyuan, W.; Hui, F. The Buck-Boost Converter Adopting Passivity-Based Adaptive Control Strategy and Its Application. In Proceedings of the 7th International Power Electronics and Motion Control Conference, Harbin, China, 2-5 June 2012; Volume 3, pp. 1877-1882.

27. Ortega, R.; van der Schaft, A.; Maschke, B.; Escobar, G. Interconnection and damping assignment passivity-based control of port-controlled Hamiltonian systems. Automatica 2002, 38, 585-596. [CrossRef]

28. Zeng, J.; Zhang, Z.; Qiao, W. An Interconnection and Damping Assignment Passivity-Based Controller for a DC-DC Boost Converter with a Constant Power Load. IEEE Trans. Ind. Appl. 2014, 50, 2314-2322. [CrossRef]

29. Pang, S.; Nahid-Mobarakeh, B.; Pierfederici, S.; Huangfu, Y.; Luo, G.; Gao, F. Toward Stabilization of Constant Power Loads Using IDA-PBC for Cascaded LC Filter DC/DC Converters. IEEE J. Emerg. Sel. Top. Power Electron. 2021, 9, 1302-1314. [CrossRef]

30. Bottrell, N.; Prodanovic, M.; Green, T.C. Dynamic Stability of a Microgrid with an Active Load. IEEE Trans. Power Electron. 2013, 28, 5107-5119. [CrossRef]

31. Kovar, J.; Kolka, Z.; Biolek, D. Symbolic Analysis of DC-DC Converters Using Generalized Averaged Model of PWM Switch. In Proceedings of the 2009 MIXDES-16th International Conference Mixed Design of Integrated Circuits \& Systems, Lodz, Poland, 25-27 June 2009; pp. 577-580.

32. Wang, J.; Mu, X.; Li, Q.-K. Study of Passivity-Based Decoupling Control of T-NPC PV Grid-Connected Inverter. IEEE Trans. Ind. Electron. 2017, 64, 7542-7551. [CrossRef]

33. Gandhi, M.R.; Rathore, S. Comparative Study of Different Passivity-Based Non-linear Control of DC-DC Boost Converter. In Proceedings of the 2019 Innovations in Power and Advanced Computing Technologies (i-PACT), Vellore, India, 22-23 March 2019; Volume 1, pp. 1-7.

34. He, W.; Ortega, R. Design and Implementation of Adaptive Energy Shaping Control for DC-DC Converters With Constant Power Loads. IEEE Trans. Ind. Inform. 2019, 16, 5053-5064. [CrossRef]

35. He, W.; Soriano-Rangel, C.A.; Ortega, R.; Astolfi, A.; Mancilla-David, F.; Li, S. DC-DC Buck-Boost Converters with Unknown CPL: An Adaptive PBC. In Proceedings of the 2018 Annual American Control Conference (ACC), Milwaukee, WI, USA, 27-29 June 2018; pp. 6749-6754. 
36. Xu, Q.; Xu, Y.; Zhang, C.; Wang, P. A Robust Droop-Based Autonomous Controller for Decentralized Power Sharing in DC Microgrid Considering Large-Signal Stability. IEEE Trans. Ind. Inform. 2019, 16, 1483-1494. [CrossRef]

37. Xu, Q.; Zhang, C.; Wen, C.; Wang, P. A Novel Composite Nonlinear Controller for Stabilization of Constant Power Load in DC Microgrid. IEEE Trans. Smart Grid 2019, 10, 752-761. [CrossRef] 